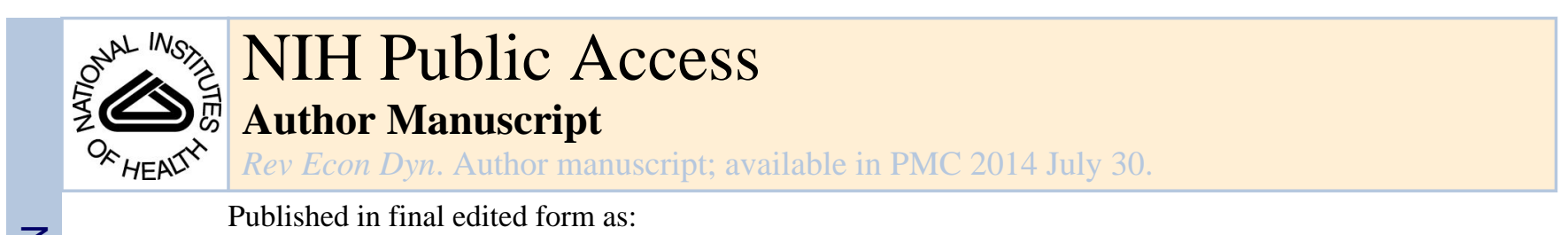

Published in final edited form as:

Rev Econ Dyn. 2009 April ; 12(2): 233-254. doi:10.1016/j.red.2008.06.003.

\title{
The dynamics of city formation
}

\author{
J. Vernon Henderson and \\ Brown University \\ Anthony J. Venables \\ University of Oxford and CEPR
}

\section{Abstract}

This paper examines city formation in a country whose urban population is growing steadily over time, with new cities required to accommodate this growth. In contrast to most of the literature there is immobility of housing and urban infrastructure, and investment in these assets is taken on the basis of forward-looking behavior. In the presence of these fixed assets cities form sequentially, without the population swings in existing cities that arise in current models, but with swings in house rents. Equilibrium city size, absent government, may be larger or smaller than is efficient, depending on how urban externalities vary with population. Efficient formation of cities with internalization of externalities involves local government intervention and borrowing to finance development. The paper explores the institutions required for successful local government intervention.

\section{Keywords}

Urbanization; city size; urban developers; city governance

\section{1: Introduction}

Understanding city formation is critical to effective policy formulation in developing countries that face rapid urbanization. While the enormous growth of urban populations in these countries is well known, the rapid growth in the number of cities is not. Between 1960 and 2000 the number of metro areas over 100,000 in the developing world grew by $185 \%$, i.e. almost tripled (Henderson and Wang, 2007). Moreover the UN's projected two billion person increase in the world urban population over the next 45 years ensures this growth in city numbers will continue. How do we start to think about why and how new cities are forming, what economic agents and institutions play critical roles in the process, whether the

\footnotetext{
*Henderson thanks the Leverhulme foundation for support as a visiting professor at the LSE. Venables' work is supported by the UK ESRC funded Centre for Economic Performance at LSE. The authors thank G. Duranton, E. Rossi-Hansberg, J. Rappaport, R. Serrano, W. Strange, and seminar participants in various forums for helpful comments. The referees and editor provided helpful comments in preparing the final version.

J. V. Henderson, Dept. of Economics, Brown University, Providence RI, USA 02912, J_Henderson@ brown.edu, http:// www.econ.brown.edu/faculty/henderson/ A.J. Venables, Dept. of Economics, Manor Road Building, Oxford, UK OX1 3UQ, tony.venables@economics.ox.ac.uk, http:// www.econ.ox.ac.uk/members/tony.venables/
} 
proliferation of cities is following a reasonably efficient growth path, and how policies may assist or constrain achievement of better outcomes?

We start with two fundamental premises which define the research agenda. The first is that city formation requires investment in non-malleable, immobile capital, in the form of public infrastructure, housing, and business capital. Our focus is on housing capital where housing is immobile and long lived, with a historical gross depreciation rate of about $1 \%$ a year and a net rate after maintenance of almost zero. We will argue that the individual housing construction decisions of competitive forward-looking builders play a key role in determining when cities start-up and when they grow, an idea new to the literature. The second premise is that, in developing countries, a key policy issue concerns how growing cities finance infrastructure investments and subsidize the development of industrial parks so as to attract businesses (World Bank, 2000). We will show that a city's ability to borrow against future incomes (or receive revenue transfers from the center) is required for an efficient growth path; yet such policies generate considerable controversy (Greenstone and Moretti, 2004 and Glaeser, 2001) and we explore reasons for the controversy.

We consider a country where the urban population is growing steadily through ongoing rural-urban migration and there are substantial sunk capital costs of housing and associated urban infrastructure. Competitive housing builders within cities are forward-looking, anticipating income streams that will be earned in new and in old cities and making individual investment decisions driving the development of cities. In the resulting equilibrium, cities form and grow in sequence. In the base case we have pure sequential growth, where first one city grows through rural-urban migration to its final stationary size, then a second city starts from zero population and grows continuously to its stationary size, and then a third and so on. We will note that it is straghtforward to extend the base case to include heterogeneity across cities, as well as technological change and adjustment costs in absorbing higher population inflows. Then, while cities still grow in sequence with much more rapid initial growth of a new city relative to older cities, they experience repeated episodes of further growth and can evolve with a size distribution consistent with Zipf's Law (Krugman 1996, Gabaix and Ioannides 2004).

The model highlights the role of housing builders, suggesting a new critical aspect of the housing market and need for robust and transparent housing market institutions such as clear title on land and housing and free entry into the building industry in efficient urban growth patterns. We solve the model under two institutional regimes. One is a regime in which there are no 'large agents': no public city governments nor private ones (large land developers). All individuals are price-takers in all markets. In this regime there are two fundamental insights of the paper.

First is that having sunk capital investments solves the coordination failure problems that are endemic to the city formation literature. In committing investment, forward looking builders anticipate future city growth and rising productivity. With sunk capital investments, equilibrium city sizes may be smaller or larger than socially optimal depending, in an intuitive manner, on the way in which externalities vary with city size. Equilibrium and 
optimal sizes may be quite "close", which, as we note below, is in stark contrast to the existing literature.

The second fundamental insight is that housing prices within cities vary over time, as growth proceeds. When a new city forms, the housing prices in old cities adjust in order to maintain occupancy in both new and old cities. While rental prices are constant in growing cities, realized incomes in those cities start low and grow as scale externalities become more fully exploited. In existing stationary cities housing prices start high (inhibiting further inmigration) when another new city first starts to grow, then they decline, and finally rise again towards the end of the growth interval of the new city. Such a cycle is a testable hypothesis, where one can compare price paths in more stationary cities in developing countries with those in the current fastest growing city. For the USA, Glaeser and Gyourko (2005) examine housing price determinants in a fully urbanized country. They find positive local shocks are associated with strong population growth of receiving cities, but have fairly modest effects on housing prices in those cities. Cities that experience negative shocks have very sharp price declines but rather modest or even zero population effects. The implication for urbanizing countries is similar: in the face of growth of another city, stationary cities retain population through price changes, while growing cities have stable prices.

The second regime we study is one in which large institutions play a role in city formation, in particular private or public city governments which have powers of taxation and borrowing. City governments borrow against future incomes in order to offer subsidies to attract new firms and migrants, during the growth period in which urban scale economies are not fully developed. As such, cities accumulate debt paid out of future tax revenues. The effect is dramatic: to smooth out realized incomes, and as a result also smooth housing price cycles. The analysis suggests that the ability of cities to subsidize entering firms relates not just to city sizes and the timing of city formation (Rauch, 1993), but also to smoothing urban incomes over time. A potentially testable implication is that countries where city governments have broad taxation and borrowing powers have smoother housing price paths in older cities and smoother income paths in newer cities, compared to countries where local governments are relatively inactive, with limited powers.

These issues we have outlined are very different from the existing literature on urbanization and city growth. The introduction of capital immobility in a dynamic context completely alters the analysis of city formation and also yields a more "realistic" city formation path. We note three problems with the current urban growth literature, which assumes perfect mobility of all resources (e.g., see handbook reviews in Duranton and Puga, 2004 and Abdel-Rahman and Anas, 2004, as well as Anas, 1992, Black and Henderson, 1999 and Rossi-Hansberg and Wright, 2007). Since there are no sunk capital costs in these models, in equilibrium there are large swings in city populations. Urbanization proceeds by the first city growing until at some point a second city forms, with the timing depending on the details of city institutions. Regardless of those, when a second city forms the first city loses half its population who migrate instantly to that second city. Then the first city resumes growth and the second city grows in parallel until a third city forms, at which point both existing cities lose $1 / 3$ of their population who migrate to this new third city. And so on. We don't see such swings in city size in the data and our model has no such swings. The second 
problem is related to the first. When new cities form in a perfect mobility context, they jump instantly to some large size, rather than grow from scratch over time to a steady state size as in the data.

Third, in the traditional literature, without the intervention of city governments or "private governments" (large scale land developers) who, through subsidies and zoning, co-ordinate en masse movement of population from old cities into a new city, there is massive coordination failure. New cities only form when existing cities become so enormously oversized that living conditions deteriorate to the point where any individual would be better off defecting from existing cities to form a "city" of size one. National urban population growth generates a dismal Malthusian tendency towards enormously oversized cities. As noted above, in our model, the irreversible investment decisions of competitive builders solves the basic coordination failure problem, so that equilibrium city sizes end up close to optimal ones. Since most developing countries lack the local institutions required to generate co-ordination of en mass movements of population, the possibility that decisions of competitive builders can solve the co-ordination problem provides a helpful perspective.

There are parts of the literature directly relevant to our central analysis. The effect of having durable, immobile capital on single city growth has been tackled in Brueckner (2000). However, the only papers that examine new city formation as the population grows with durable capital are a thesis chapter of Fujita published in 1978 and Cuberes (2004). Fujita examines planning, but not market solutions. Cuberes in a paper written simultaneously and independently of ours has an empirical focus, with a motivating model that has only two cities in total that ever form in the economy. Cuberes doesn't analyze the role of institutions in driving different types of equilibria, housing price cycles, and the general topics in this paper. This paper develops a model of city formation under immobility of capital, building on Venables (2005) who illustrates that population immobility will affect the city formation process. There is a complementary paper on city formation with durable capital by Helsley and Strange (1994) in which large private governments form cities simultaneously in a static context, using durable capital as a strategic commitment device. We have a dynamic context and for much of the paper there are no local governments; but the Helsley and Strange paper introduces the idea that durable capital can overcome coordination failure.

The next two sections present the model and derive the benchmark first best planning solution. Section 4 analyses a market solution without local governments, developing the key results in the paper concerning the role of builders and immobile capital. Section 5 compares the equilibrium and the optimum; and introduces local governments than internalize externalities and smooth income and price paths, highlighting the institutions required in this context and the debt accumulation path of growing cities. Section 6 discusses extensions involving heterogeneity, technological change and limited rural-urban migration. Section 7 concludes.

\section{The model}

In order to isolate the key elements in the urbanization process, we make a number of simplifying assumptions. First we assume a small open economy where agents can borrow 
and lend at a fixed interest rate $\delta$ in world capital markets. We do not embed the process in a closed economy model with capital accumulation and an endogenous interest rate. Second, we assume that the urban sector grows in population by a constant amount, $v$, each instant, as if there were a steady stream of population out of agriculture and into the urban sector. Constancy of this rate is not critical to the concepts developed in the paper. For example, if the migration rate to cities responded to rural-urban income differences, while that could affect city population growth rates, it would not affect the process of how new cities form or the analysis of policies and institutions. Third, in the base case, we abstract from ongoing technological change which would tend to increase equilibrium and efficient city sizes over time. Finally to derive the key results, we assume repilcability: that all cities form under identical circumstances - technology, amenities, and industrial composition. In Section 6, we discuss the robustness of our key insights to the introduction of heterogeneity, technological change and a limited horizon for population growth. We start with a description of a city in the economy, setting out both the urban agglomeration benefits and the urban diseconomies associated with city population growth.

Cities form on a "flat featureless plain" with an unexhausted supply of identical city sites, and land is available for urban development at zero opportunity cost. There are $n(t)$ workers in a particular city at date $t$ and we define a worker's real income, $w(t)$, as

$$
w(t)=x(n(t))-c n(t)^{\gamma-1}-h(t)+s(t) .
$$

As we will see, the first term is the worker's output, the second is land rent plus commuting costs, the third is housing rent and the final term is any subsidy (or, if negative, a tax) that the worker receives. This real income expression contains all the components of earnings, subsidies, and expenditures and define the amounts available to be spent on consumption of the numeraire good. We discuss each of the components of (1) in turn.

\section{Production}

Firms in a city produce a single homogenous good with internal to the firm constant returns to scale, but subject to citywide scale externalities. Given firm level constant returns, we assume that each worker is also a firm. Under urban scale economies, workers benefit from interaction with each other, with per worker output rising at a decreasing rate with city population. ${ }^{1}$ Formally, the city work force is $n$ and per worker output is $x(n)$, with $x^{\prime}(n)>0$, $x^{\prime \prime}(n)<0$. We also assume that as $n \rightarrow 0, x(n) \geq 0$, and $x^{\prime}(n)$ is bounded away from infinity.

\section{Commuting and land rent}

The second term on the right-hand side of equation (1) is land rent plus commuting costs in a city of size $n(t)$. While commuting costs are modelled as out-of-pocket, they could be modelled as a source of disutility. All production in a city takes place in the city's central business district (CBD), to which all workers commute from residential lots of fixed size. Free mobility of workers requires all workers in the city to have the same disposable income

\footnotetext{
${ }^{1}$ These urban scale economies can be given a variety of micro foundations ( Duranton and Puga, 2004).
} 
after rent and commuting costs are paid. Thus, there is a land rent gradient such that, at all points within the city, land rent plus commuting costs per person equal the commuting costs of the edge worker whose rent is zero. Edge commuting costs take the form $c n(t)^{\gamma-1}$ (the term in (1)) which is derived, along with expressions for rent and commuting costs, in Appendix 1. The parameter $c$ measures the level of commuting costs and $\gamma$ combines relevant information on the shape and commuting technology of the city, in a modest generalization of the standard approach in the urban literature (Duranton and Puga, 2004) to allow for different shape cities and for commuting costs which are an iso-elastic function of distance. If commuting costs per unit distance are constant then, in a linear city $\gamma=2$, and in a circular or pie shaped city $\gamma=3 / 2$. Our basic restriction is that $\gamma>1$, so average commuting costs, as well as average land rent, rise with city population. Integrating over the commuting costs paid by people at each distance from the centre and over their rents gives the functions $T C(n)$ and $T R(n)$ reported in Table 1.

\section{Housing}

A plot of city land can be occupied by a worker only after a fixed capital expenditure of $H$ has been incurred. This represents the construction of a "house", which could conceptually include infrastructure such as roads, sewerage, water mains, and energy delivery. The housing construction, sale, and rental markets are all assumed to be perfectly competitive, and the spot market rent of a house at time $t$ is denoted $h(t)$, this paid in addition to the rent on land. Throughout the paper we assume that the two rent components are separable; housing rent, $h(t)$, is paid separately from land rent which is determined by the city land rent gradient. We also assume that the two sources of income can be taxed separately. Under this separation, house builders may rent land from land owners with an infinite lease and pay land rents according to the perfectly foreseen city land rent gradient. Alternatively builders could initially buy the land from the land owners, capitalizing the land rents. And a model with owner-occupancy where residents buy land and housing would yield equivalent results. Land owners are people outside the urban sector, although the same results on city formation hold if they are nationwide Arrow-Debreu share holders in the land of all cities. ${ }^{2}$ While we assume housing does not depreciate, it is a minor adjustment to have depreciation which would be offset by maintenance as long as a lot is occupied. Assumptions fixing lots sizes and housing consumption are made for tractability. Changing them does not change the conceptual findings, but would allow for more nuanced considerations such as shrinking lot sizes as cities grow larger and land rents rise (even under full dynamic optimization). The really critical assumption is that some sufficiently large sunk investment has to be made for each urban worker.

\section{Subsidies and taxes}

The final term in equation (1) denotes a per worker subsidy at rate $s(t)$ (tax if negative) to workers in the city at date $t$. Since workers are also firms, the subsidy could be viewed as going to firms, a common element of city finance. We investigate use of subsidies in Section 5.

\footnotetext{
${ }^{2}$ In this case we would add an income term to (1), the worker's share in national urban land rents, which is perceived as fixed by any worker.
} 
Table 1 summarizes key relationships in a city with population $n$. The left-hand block of the table reports the basic relationships between commuting costs and land rent, derived in Appendix 1. The right-hand block defines relationships which we will use repeatedly through the paper and which, for convenience, combine the technologies of production, commuting, and urban land rent. Total surplus, $T S(n)$, is the output minus commuting costs of a city of size $n$; notice that this is defined excluding housing costs. Average surplus $A S(n)$ and marginal surplus $M S(n)$ follow in the usual way. $L S(n)$ is the surplus per worker after subtracting average land rent paid to landowners, $L S(n) \equiv A S(n)-A R(n)$; or it is wage income net of land rent and commuting costs for any worker before subsidies, to be spent on housing and all other goods. It follows from equation (1) that $w(t)=L S(n(t))-h(t)+s(t)$. Finally, $E X(n)=M S(n)-L S(n)$ is the production externality associated with adding a worker-firm to the city: it is the increase in output of all other workers in the city when a further worker is employed.

The shapes of these functions are critical, and we state assumptions that are sufficient for the propositions that follow.

A1 $L S(n)$ is strictly concave in $n$ with unique interior maximum at $n_{L}$, $x^{\prime}\left(n_{L}\right)=n_{L}^{\gamma-2} c(\gamma-1)$, and such that as $n \rightarrow \infty, L S(n)<L S(0)$.

Notice that if $\gamma<2$ then this assumption is stronger than concavity of $x(n)$. From A1, it follows that $A S(n)$ is strictly concave (since $\gamma>1$ ), but we also assume:

A2

$A S(n)$ has interior maximum at $n_{A}, x^{\prime}\left(n_{A}\right)=n_{A}^{\gamma-2} c(\gamma-1) / \gamma$.

A1 and A2, together with $\gamma>1$ and our assumptions on $x(n)$ imply that: (i) $n_{A}>$ $n_{L}$. (ii) $M S(0)=A S(0)$. (iii) $M S(n)$ intersects $A S(n)$ from above at $n_{A}$. $M S(n)$ is initially increasing and is decreasing for all $n>n_{A}$, since after $n_{A}, M S^{\prime}(n)=2 A S^{\prime}$ $(n)+n A S^{\prime \prime}(n)<0$. However, in characterizing the planning solution to ensure pure sequential growth, as in Fujita (1978), we assume explicitly that the total surplus curve, $\operatorname{TS}(n)$, has the textbook S-shape, or that:

A3 Starting from $n=0, M S(n)$ is strictly increasing in $n$ until it peaks, after which it is strictly decreasing.

Figure 1 illustrates these relationships. The average surplus curve has a maximum at point $n_{A}$. Marginal surplus and average surplus start at the same point, then marginal lies above average until they intersect at $n_{A}$. Surplus net of land rents, $L S(n)$, lies below $A S(n)$, with a maximum at $n_{L}<n_{A}$.

Our analysis also requires an assumption that the magnitude of housing construction costs, $H$, be large enough to ensure that housing is never left empty; this prevents jumps in city size. The issue arises in different contexts and here we state a condition sufficient to apply in all cases:

A4 $\delta H \geq A S\left(n_{A}\right)-A S(0) ; L S(0)=A S(0)>\delta H$.

The first part of A4 states that the interest charge on housing per worker is at least as large as the difference between the maximum level of surplus per worker and its level in a new city with zero initial population. The second part of A4 ensures that urbanization will occur 
because migrants are willing to pay rents to be in cities. The first part implies that housing costs are high relative to net agglomeration benefits of cities, and the aptness of the assumption could be debated empirically. We note that assumption A4 is an all-purpose sufficient condition; in each of the situations we examine only lower relative magnitudes of housing costs are necessary. As we will see, the assumption ensures that, in equilibrium, new cities do not start off jumping to some discrete size, drawing population from existing cities so that some portions of the housing stock in those cities are temporarily unoccupied. We note that, in the USA, even cities experiencing large negative shocks typically have little unoccupied housing (apart from that driven by the usual housing market search frictions found in all markets). Adjustment as would be predicted in our framework is not through vacancies developing but rather through housing price declining to retain the population (Glaeser and Gyourko, 2005). Note we have also implicitly assumed no other fixed start-up costs to a new city. Such a possibility could result in temporarily unoccupied housing in existing cities, as some of the population they have "stored" is used to create a required discrete size new city. Again, relaxing these assumptions which are made for tractability and allowing for temporary vacancies leaves the basic insights concerning co-ordination failure unchanged.

\section{Socially optimal city formation}

Population, arriving at $v$ per unit time, flows into one or more new cities. How should this population be allocated across cities over time? Fujita (1978) wrote a book solving this problem in different and often more complex contexts, albeit without the market and institutional analyses which is the subject of this paper. Given Fujita's detailed solution, we focus on providing intuition and a summary proposition.

The objective is the present value of the total surplus, net of housing costs, of the entire city system. Distinguishing individual cities by subscripts, the population of city $i$ at date $t$ is $n_{i}(t)$ and the optimisation problem is to choose flows into each city, $\dot{n}_{i}(t)$, to maximise:

$$
\begin{gathered}
\Omega=\int_{0}^{\infty} \sum_{i} T S\left(n_{i}(t)\right) e^{-\delta t} d t-\int_{0}^{\infty} \nu H e^{-\delta t} d t \\
\text { subject to } \quad \sum_{i} \dot{n}_{i}(t)=\nu, \\
\dot{n}_{i}(t) \geq 0 \quad \forall i .
\end{gathered}
$$

The first term in the objective is the present value of the surplus generated by all cities that ever form, and the second term subtracts from this the cost of housing. The first constraint with mutiplier $\lambda(t)$ has total population changes across all cities sum to the national flow, $v$. The remaining constraints with multipliers $\gamma_{i}(t)$ restrict each city to never contract. As a consequence (since there is continuous population inflow) there are no upwards jump in the population of any city. We impose this as a constraint here, and show in appendix $2 \mathrm{C}$ that assumption A4 is sufficient for it to be satisfied. Notice that with this constraint there are never unoccupied houses in the urban system so the total cost of housing, the final term in the objective, is the same regardless of the city structure.

Necessary conditions for optimality are the Euler equations and transversality conditions, 


$$
\begin{gathered}
\dot{\gamma}_{i}(t)-\dot{\lambda}(t)=M S\left(n_{i}(t)\right) e^{-\delta t} \quad \forall i, t \\
\lim _{t \rightarrow \infty} \gamma(t)=\lambda(t)=0 .
\end{gathered}
$$

If city $i$ is growing at date $t$, then $\dot{n}_{i}(t)>0$, so $\gamma_{i}(t)=0$. Thus, if a pair of cities $i, j$ are growing simultaneously they must have $M S\left(n_{i}(t)\right)=M S\left(n_{j}(t)\right)$ and hence be identical with $n_{i}(t)=n_{j}(t)$. This condition rules out many possibilities; for example, it cannot be optimal to start a new city during a period when an existing city is continuing to grow. Optimality requires either a single city growing at any one time, or multiple identical cities growing in parallel. Integrating the Euler equation forwards from date $z$ gives condition

$$
\begin{gathered}
\mu_{i}(z)=\int_{z}^{\infty} M S\left(n_{i}(t)\right) e^{-\delta(t-z)} d t \\
\text { where } \mu_{i}(z) \equiv\left(\lambda(z)-\gamma_{i}(z)\right) e^{\delta z}>0
\end{gathered}
$$

$\mu_{i}(z)$ has natural interpretation as the shadow value of an additional worker entering city $i$ at date $z$, equal to the present value of the marginal surplus created by the worker. At any date $z$ when there are existing cities which are not currently growing, for optimality these stationary cities must have a common shadow value, which we denote $\mu(z)$. If these cities remain stationary at all future dates, then they must have a common size, given

$$
\hat{\mu}(z)=\int_{z}^{\infty} M S(\nu T) e^{-\delta(t-z)} d t
$$

where $T$ is the length of time each of these cities has grown in the past and $v T$ is their stationary population. Consider a new city $i$, which starts growing at date $\tau$ and grows at rate $v$ until date $\tau+T$ when it stops. We can check the optimality of this by looking at $\mu_{i}(z)-\mu$ (z) for dates $z \in[\tau, \tau+T]$. This is,

$\mu_{i}(z)-\hat{\mu}(z)=\int_{z}^{\tau+T} M S(\nu(t-\tau)) e^{-\delta(t-z)} d t+\int_{\tau+T}^{\infty} M S(\nu T) e^{-\delta(t-z)} d t-\int_{z}^{\infty} M S(\nu T) e^{-\delta(t-z)} d t$.

The first two terms on the right hand side split the shadow value of city $i$ into the part when it is growing, so has population $v(t-\tau)$ and when it is stationary. Combining the last two terms

$$
\mu_{i}(z)-\hat{\mu}(z)=\int_{z}^{\tau+T}[M S(\nu(t-\tau))-M S(\nu T)] e^{-\delta(t-\tau)} d t, \quad z \in[\tau, \tau+T]
$$

From this expression, we can see that it is optimal to grow city $i$ during interval $z \in[\tau, \tau+$ $T]$ if;

i. At start date $\tau, \mu_{i}(\tau)-\hat{\mu(\tau)}=0$. Optimality over the growth period of the city, requires

$$
\int_{\tau}^{\tau+T}[M S(\nu(t-\tau))-M S(\nu T)] e^{-\delta(t-\tau)} d t=0 .
$$


ii. At stopping date $\left.\tau+T, \mu_{i}(\tau+T)-\hat{\mu(\tau}+T\right)=0$. This follows from (7); the integral is zero because city $i$ becomes identical to existing cities.

iii. At dates $z \in[\tau, \tau+T], \mu_{i}(z)-\hat{\mu(z)}>0$. This holds because the function $M S(v t)$ is single peaked (Appendix 2A) and says that the shadow value of adding a resident to the current growing city is greater than that of adding a resident to a stationary city. It implies that in the interval $z \in(\tau, \tau+T)$, it is better to continue expanding the current growing city than to start a new city. ${ }^{3}$ Single peakedness also implies that there is a unique value of $T=T_{\text {opt }}$ solving equation (7), as shown in appendix 2A. This analysis implies that the shadow value of adding a worker to the current growing city exceeds the shadow value of using that worker to start a new city, as long as $z<\tau+T$ (for any growth path a new city might follow). It is inefficient to halt growth of a new city until $z=\tau+T$.

This establishes that sequential growth by single cities each growing for $T_{o p t}$ satisfies the first order conditions. Parallel growth by some number of cities $k>1$ also satisfies the first order conditions, by the same analysis but with $v$ replaced by $v / k$, and $T$ adjusting accordingly. However, this yields a lower value of the objective, as gains from increasing returns are postponed (appendix 2B). Finally, we imposed that $\dot{n}_{i}(t) \geq 0$, ruling out the possibility that population goes temporarily into existing cities and then moves out, allowing a new city to jump discontinuously to some discrete size. A jump has the advantage of delivering returns to scale instantaneously, but the cost of jumps is that housing is left empty in old cities. This cost depends on the magnitude of the sunk housing costs, $H$, and in appendix $2 \mathrm{C}$ we show that assumption $\mathrm{A} 4$ is sufficient to rule out such jumps.

This analysis yields the following proposition.

\section{Proposition 1}

I. In an efficient city system cities form and grow strictly in sequence, each growing without interruption to their final size. The period of growth is the value $T=T_{\text {opt }}$ solving

$$
\int_{0}^{T}[M S(\nu t)-M S(\nu T)] e^{-\delta t} d t=0, \quad(7)
$$

and the associated population is $n_{\text {opt }}=v T_{\text {opt }}$.

II. Given $\delta>0$, city size is larger than that which maximizes surplus per worker, $n_{o p t}>$ $n_{A}$.

Proof: Equation ( $\left.7^{\prime}\right)$ is (7) with time set so that $\tau=0$. Uniqueness of $T_{\text {opt }}$ and part (II) are proved in appendix $2 \mathrm{~A}$.

The intuition behind condition $\left(7^{\prime}\right)$ is that city size is chosen so that the present value of the marginal surplus from adding a worker to a new city, $M S(v t)$, equals the present value over

\footnotetext{
${ }^{3}$ The present value of the marginal surplus from $s$ onwards in the current growing city minus the present value of the surplus of a new city founded at time $s$ and growing for an interval $T$ before stopping reduces to equation (6).
} 
the same time frame of the marginal surplus from adding the worker to an existing city, $M S(v T)$. Light can be shed on part II by observing that $\left(7^{\prime}\right)$ can be integrated by parts to give

$$
\int_{0}^{T_{o p t}}\left[M S(\nu t)-M S\left(\nu T_{o p t}\right)\right] e^{-\delta t} d t=\frac{T S\left(\nu T_{o p t}\right) e^{-\delta T}}{\nu}+\frac{\delta}{\nu} \int_{0}^{T} T S(\nu t) e^{-\delta t} d t-M S\left(\nu T_{o p t}\right) \int_{0}^{T_{o p t}} e^{-\delta t} d t=0
$$

If $\delta=0$ this reduces to $T S\left(v T_{\text {opt }}\right) / v T_{\text {opt }}=M S\left(v T_{\text {opt }}\right)$, i.e. the equality of average and marginal surplus. In the absence of discounting, the optimal city size is therefore at the maximum of $A S$ with $n_{\text {opt }}=n_{A}$. A positive discount rate increases $T_{\text {opt }}$, giving $n_{\text {opt }}>n_{A}$, because discounting makes it more costly to bring forward the low values of average surplus associated with early years of a new city. This can be established by differentiating (8) to show that $d T / d \delta>0$. The result is intuitive. A higher discount rate puts more weight on the low surpluses that are initially earned in a new city, discouraging city formation.

\section{Competitive equilibrium without city governments}

Given this benchmark, we now turn to equilibria under different institutional settings, starting with the situation in which there are neither public governments nor private ones in the form of large property developers who might internalize externalities. We continue to assume that all potential cities have identical technologies, and establish that there is an equilibrium in which cities grow strictly in sequence; there is a length of time $T_{e q}$ for which a new city grows before it becomes stationary and growth commences in the next new city. We then argue that an equilibrium with sequential city growth is the only "stable" equilibrium. In this section there is no government so $s_{i}(t)=0$, but we carry subsidy terms through initial equations for reference in Section 5. Assumptions on technology are relaxed in section 6.

There are three types of economic agents, all price takers operating in competitive markets.

i. Landowners, who are completely passive and simply receive rent according to the city land rent gradient, as discussed in Section 2.

ii. Workers, who are perfectly mobile between cities and occupy one house in the city in which they work. This mobility implies that equilibrium real income $w(t)$ must be the same in all cities. From equation (1) and the definition of $L S$ (Table 1), mobility implies that at any date, $t$, and in any city, $i$, given the common $w(t)$, house rents satisfy

$$
h_{i}(t)=L S\left(n_{i}(t)\right)+s_{i}(t)-w(t) .
$$

iii. Builders, who construct and own housing which they rent to residents. Housing is available on a spot rental market, and house construction requires sunk cost $H$. Builders have perfect foresight and maximise the present value of profits earned on construction of a house. They take as given the equilibrium $w(t)$ path and the consequent $h_{i}(t)$ paths from equation (9). We denote the present value of profits for a builder in city $i$ with construction date $z$, by $\Pi_{i}(z)$, 


$$
\Pi_{i}(z) \equiv \int_{z}^{\infty} h_{i}(t) e^{-\delta(t-z)} d t-H . \quad(10)
$$

Since houses are always occupied (a consequence, as we shall see, of assumption A4), housing construction is going on in city $i$ if and only if the city is growing. Competition amongst builders gives zero profits in cities where construction is occurring and nonpositive to construction elsewhere so

$$
\begin{gathered}
\Pi_{i}(z) \leq 0, \quad \dot{n}_{i}(z) \geq 0, \quad \text { complementary slack; } \\
\sum_{i} \dot{n}_{i}(z)=\nu .
\end{gathered}
$$

An implication of (11) is what we call the 'no-switch condition'. In equilibrium, if at some date $z$ city $i$ is growing and city $j$ is stationary, then

$$
\Pi_{i}(z)-\Pi_{j}(z)=\int_{z}^{\infty}\left[h_{i}(t)-\hat{h}_{j}(t)\right] e^{-\delta(t-z)} d t=\int_{z}^{\infty}\left[L S\left(n_{i}(t)\right)+s_{i}(t)-L S\left(n_{j}(t)\right)-s_{j}(t)\right] e^{-\delta(t-z)} d t \geq 0
$$

where $^{\wedge}$ denotes an existing stationary city and the second equation uses (9). Equation (12) states that builders will not deviate to switch from building in city $i$ to city $j$, because the present value of rents in $i$ is at least as large as that in $j$.

Given these conditions, we characterise the equilibrium with the following proposition. In this situation since subsidies are zero, the proposition is stated and proved for $s_{i}(t)=0$.

Proposition 2-There is a perfect foresight competitive equilibrium (without city government and in which cities have identical technologies) in which cities grow strictly in sequence and:

I. Each new city grows uninterrupted for a length of time $T_{e q}=T$ where $T$ solves

$$
\int_{0}^{T}[L S(\nu t)-L S(\nu T)] e^{-\delta t} d t=0, \quad(13)
$$

and the associated final population of each city is $n_{e q}=v T_{e q} . v T_{e q}>n_{L}$, where $n_{L}$ is the size which maximises labour surplus.

II. Workers' real incomes, $w(t)$, first increase and then decrease during the growth of each new city, and this is transmitted to existing cities via variation in house rents in those cities.

Proof: Mobility of labour between cities implies that real incomes are equalised across cities at any instant, and this is secured by house structure rents adjusting so that for any pair of cities, $i, j$, (from (9))

$$
h_{i}(t)-h_{j}(t)=L S\left(n_{i}(t)\right)-L S\left(n_{j}(t)\right)
$$


Let city $i$ be a new city which starts growing at time $\tau$ and absorbs all migrants. While the city is growing, $z \in[\tau, \tau+T]$, builders earn zero profits, $\Pi_{i}(z)=0$; differentiating (10), this implies

$$
h_{i}(z)=\delta H .
$$

This says that rents in a growing city equal the interest charge on new housing, $\delta H$. In existing cities, population is $v T$, so using (15) in (14), housing rents in existing cities are

$$
\hat{h}_{j}(z)=L S(\nu T)-L S(\nu(z-\tau))+\delta H
$$

Strictly sequential growth can only be an equilibrium if it is not more profitable to build in existing cities, compared to the current growing city. This is the no-switch condition, and using (15) and (16)

$\Pi_{i}(z)-\hat{\Pi}_{j}(z)=\int_{z}^{\tau+T_{i}}\left[L S\left(\nu(t-\tau)-L S\left(\nu T_{j}\right)\right] e^{-\delta(t-z)} d t+\int_{\tau+\tau_{i}}^{\infty}\left[L S\left(\nu, T_{i}\right)-L S\left(\nu T_{j}\right)\right] e^{-\delta(t-z)} d t \geq 0, \quad z \in\left[\tau, \tau+T_{i}\right]\right.$.

in (12),

The difference in the present value of profits is broken into two parts: the integrals up to date $\tau+T_{i}$, the date when city $i$ stops growing, and integrals for terms beyond $\tau+T_{i}$. For an equilibrium we require three conditions:

i. At starting date, $z=\tau, \Pi_{i}(\tau)=\Pi_{j}(\tau)=0$. At the instant of construction switching to city $i$ from the previous growing city, $j$, profits in both cities are zero.

ii. $\quad T_{i}=T_{j} \equiv T$ so that at the stopping date, $z=\tau+T, \Pi_{i}(\tau+T)=\hat{\Pi_{j}}(\tau+T)=0 .{ }^{4}$

Conditions (i) and (ii) give equation (13) of the proposition (with time set such that $\tau=0)$. As in the proof of proposition 1, single peakedness to the function $L S(v t)$ implies that there is a unique value of $T$ satisfying (13). These conditions also imply that $L T(v T)>L S(0)$ and $v T_{e q}>n_{L}$. See appendix 3 .

iii. For $z \in[\tau, \tau+T],(17)$ is satisfied with inequality, which is the no-switch condition in (12) in this situation. It follows because $L S(v t)$ is single peaked as shown in appendix 3 .

Part (II) of the proposition follows similarly from the fact that $w(z)=L S(v(z-\tau))-$ $\delta H$ first rises and then declines for $z \in[\tau, \tau+T]$. From equation (16), rents in existing cities start high, decline and then rise again towards the end of the growth interval. From appendix $3, \hat{h}(t)>0$, ensuring houses are always occupied in existing cities.

\footnotetext{
${ }^{4}$ An issue concerns whether there could possibly be a sequence of $T$ 's of different values (e.g., $T_{j}<T_{i}$ ) which satisfy repeated application of (17), with the second term on the RHS being non-zero. If such a sequence could exist, we rule it out by applying 'stationarity' in the spirit of Duffie, Geanakoplos, Mas-Colell, and McLennan (1994) or Baron and Ferejohn (1989). If builders who build in cities $i$ and $j$ switch places in time, so those who build in $j$ now build earlier in $i$ and those in $i$ now build later in $j$, we require these builders take the same actions with the same outcomes, given the fundamentals are unchanged.
} 
The time paths of income and housing structure rent are illustrated in Figure 2. The top line gives the output minus land rent and commuting costs of a worker in a city founded at date $0, L S(v t)$. During the life of the city this rises to a peak at $T_{L}$, and then starts to decline until date $T_{e q}$ is reached, after which it is stationary. The worker also pays housing rent which, during the growth of the city is simply $\delta H$. The worker's real income net of housing costs is the difference between these, given by the middle line $L S(v t)-\delta H$, which varies over the life of the city.

In the time interval $\left[T_{e q}, 2 T_{e q}\right]$ another city is growing and offering its inhabitants the income schedule $L S(v t)-\delta H$. Workers are mobile, and remain in the first city only if rents follow the path $\hat{h}(t)$ (equation 16). Thus, there are housing rent cycles in old cities as the housing market adjusts to conditions in the current growing city, to maintain equilibrium in worker location decisions across cities. As illustrated in Figure 2 house rents in old cities jump up when a new city is born as this city is initially unattractive; they are then U-shaped, reaching $\delta H$ at the point where the new city is the same size as old ones. The process repeats indefinitely with periodicity $T_{e q}$, so stationary cities have a rent cycle in response to the possibility of migration to the growing city.

Viewing Figure 2, one might ask why, once a new city starts, builders do not continue to build in old cities in which rents are higher. Once building starts in a new city (at dates $T_{e q}$, $2 T_{e q}$, etc) initial builders in the new city know that they will be followed by further builders in that city. The key is that housing investment is irreversible; any further housing built in old cities cannot be moved to a new city when rents in old cities start to fall. One can also use Figure 2 to gain further insight into the equilibrium by considering alternative $T$ to $T_{e q}$ as candidate equilibrium values. ${ }^{5}$

\subsection{Uniqueness and stability of Equilibrium}

Proposition 2 characterizes an equilibrium in which cities form in sequence and each grow to the same size. However the equilibrium we describe is not unique. There are also equilibria with sequential growth, but with multiple cities growing in parallel during each sequence. Such cities have to be identical; $L S\left(n_{i}(t)\right)$ must have the same value for equation (14) to hold with rents $\delta H$. Thus, if there were $k$ growing cities the population of each city $t$ periods into its growth would be $v t / k$ and the proof of proposition 2 goes through as above, but with $v$ replaced by $v / k$. However, we think it reasonable to concentrate on the equilibrium with a single city growing at each date, $k=1$, by a stability argument. If, at any date close to the start of the cities' growth, a slightly higher share of migrants goes to one city relative to the other growing cities then, since $L S\left(n_{i}(t)\right)$ is an increasing function, the return to workers in this city will rise relative to the others. From equation (9), rents that can be charged in the other growing new cities would fall below $\delta H$, so that building would cease in these other cities.

\footnotetext{
${ }^{5}$ Suppose that the first city stops growing just before $T_{e q}$. Then its $L S\left(v T_{e q}\right)$ would be somewhat greater, which shifts up its $\hat{h}(t)$ curve at all future dates, given the path $L S(v t)-\delta H$ of new growing cities. This means that future house rents in this city would be higher, making it profitable to continue building, rather than stopping and switching to a new city. And if a city grows past $T_{e q}$, that lowers $L S\left(v T_{e q}\right)$ and shifts down the $\hat{h}(t)$ path the builder will receive once the city is stationary, lowering rents so that their present value will no longer cover housing cost.
} 
An alternative approach to the problem would be to structure a game where it is sequentially rational only for builders and migrants all to enter the same growing city until it reaches size $v T_{e q}$, before then switching to a new city. In a potential equilibrium where they split across multiple cities, it pays any builder and migrant to deviate to move to another growing city since that would raise income, $L S$, and chargeable rent, following the same logic as the stability argument. We footnote the outline of a three stage game played at each instant starting from time zero when cities first start to form, where the equilibrium is unique in both prices and development paths. 6

\subsection{Other Aspects of the Equilibrium}

In the next section we turn to comparing the equilibrium with the social optimum, but now make a few further remarks about the equilibrium. First, city size is greater the larger is the discount rate. This property is the same as for the optimum, and the proof follows from replacing the function $M S$ by the function $L S .^{7}$

Second, equation (13) can be rearranged to read

$$
\int_{0}^{T} L S(\nu t) e^{-\delta t} d t+\frac{e^{-\delta T}}{\delta} L S(\nu T)=\frac{1}{\delta} L S(\nu T)
$$

The left-hand side is the present value of income for the first person in a new city; and the right-hand side is the present value of the alternative, entering an old city. These are

\footnotetext{
${ }^{6}$ The game considers only stationary equilibria in the spirit of Duffie, Geanakoplos, Mas-Colell and McLennan (1994). Second, it treats agents as discrete, while, in a continuous time formulation, agents are atomless. This problem is resolved by requiring the continuum equilibrium to be an equilibrium in a finite approximation setting. Finally, the potential Bertrand pricing indeterminancy problem with inelastic housing demand is solved by an appropriate staging of the game. At each instant, in stage 1 owners of all existing housing announce the spot prices at which they commit to rent their house that instant. In stage 2 an endogenous number of new builders enters from the pool of potential builders. Playing in a predetermined sequence, each builder decides whether to enter; and, if she enters, commits to provide a house in a particular city at an announced spot rent at that instant. In stage 3, the new (current migrants) and existing urban population choose simultaneously where to live, production occurs, and incomes and prices are paid. If we start the evolution of city development in the economy from time 0 , there is a unique equilibrium path. We illustrate some aspects of the game.

In time 0 , there are no existing houses. At that instant, in stage 2, the first builder enters, chooses a city, and announces rent $\delta H$. At time 0 , the second builder has a choice- either join the first or go to a new location. This builder anticipates stage 3 where, if all $v$ builders each charging $\delta H$ have entered the same city in stage 2, that city will attract all migrants in stage 3, compared to any potential smaller city with spot rents of at least opportunity $\operatorname{cost} \delta H$, since $L S$ is initially rising. If the second builder chooses a new location, subsequent builders would join him with at most probability .5 , so he runs the risk of a loss. Given this, the rational choice is to join the first city, as it is for subsequent builders. Note that if any builder announces more than $\delta H$, a $v+1$ builder would enter in stage 2 and the deviator's house would be unoccupied (this is the result previously from differentiating equation (10)). Finally in this first instant, in stage 3, the first migrants choose a house at the announced rent. At the second instant, in stage 1, old builders announce spot prices, anticipating stage 2 , where $v$ builders will enter the first city each offering spot rent $\delta H$. Note if stage 1 prices are announced to exceed $\delta H$, it pays any stage 1 owner to deviate because such a stage 1 pricing profile would induce $2 v$ builders to enter in stage 2 each charging just under the announced stage 1 price. In stage 3 all houses offered in stage 1 would be empty. Stages 2 and 3 in the second instant proceed as for the first instant and the process continues until the first city reaches size $v T_{e q}$.

At $T_{e q}$, new builders switch to a new city. First, the same logic in the game as for the first city dictates that only one new city forms at $T_{e q}$. Second, no builder would deviate from building in a new city at $T_{e q}$, to resume construction in the old, given

$d\left\langle\int_{0}^{T}[L S(\nu t)-L S(\nu(T))] e^{-\delta t} d t\right\rangle / d T<0$. Similarly, if the old city were to grow longer than $T_{e q}$, a builder in stage 2 would profitably deviate to build in a new city. And no builder would deviate to start to build in a second city before $T_{e q}$ : the other builders would enter in stage 2 to supply migrants in stage 3 at price $\delta H$ in the old city and the new city wouldn't be unoccupied. Finally relative to the rents charged in old cities when they stop growing after time $T$, in stage 1 , there is not a pricing equilibrium with higher rents. As discussed above, that would lead to entry of additional builders in stage 2 in the new city and the risk for stage 1 suppliers of having unoccupied housing, inducing stage 1 price competition until prices equal those given in (16).

${ }^{7}$ For other comparative statics, it is possible to show that a faster rate of population inflow, $v$, reduces $T_{e q}$, although it has an ambiguous effect on city size $v T_{e q}$
} 
equalized at the switch point of migration into a new city, where migrants are indifferent between migrating permanently to a new versus an old city. This equation arises in Venables (2005) where, once migrants have chosen a city, they are assumed to be perfectly immobile thereafter. Here this equation is satisfied not because of an assumption of immobility, but because of sunk housing costs. Builders choosing to build in the city with the highest present value of rents; this yields the same outcome as workers choosing to live in the city that yields the highest present value of incomes.

A further property of the equilibrium is that workers who happen to enter the urban system in the middle of a city's growth period receive a higher present value of income than those who enter at the beginning or end. This follows because, as we showed in the proof of

Proposition $2, \int_{z}^{\tau+T}\left[L S(\nu(t-\tau)-L S(\nu T)] e^{-\delta(t-z)} d t \geq 0, z \in[\tau, \tau+T]\right.$, with strict inequality between endpoints. Entrants at these intermediate dates get a "surplus", by avoiding the low incomes of a start-up city. ${ }^{8}$ This surplus plays a key role in the analysis of city government behavior later, where surpluses are, in essence, taxed away.

\section{Equilibrium versus Optimum}

In this section we discuss the efficiency of equilibrium. Are equilibrium city sizes too large or too small? Then we ask what national government policies or national market institutions would generate optimality.

Proposition 3-The competitive equilibrium without city government gives larger cities than optimum, $T_{e q}>T_{o p t}$, if

$$
\int_{0}^{T_{o p t}}\left[E X(\nu t)-E X\left(\nu T_{o p t}\right)\right] e^{-\delta t} d t>0
$$

and conversely.

Proof: From table 1, $E X(n)=M S(n)-L S(n)$. Using equations $\left(7^{\prime}\right)$ and (13),

$$
\int_{0}^{T_{o p t}}\left[E X(\nu t)-E X\left(\nu T_{o p t}\right)\right] e^{-\delta t} d t=\int_{T_{o p t}}^{T_{e q}}\left[L S(\nu t)-L S\left(\nu T_{e q}\right)\right] e^{-\delta t} d t+\int_{0}^{T_{o p t}}\left[L S\left(\nu T_{o p t}\right)-L S\left(\nu T_{e q}\right)\right] e^{-\delta t} d t
$$

\footnotetext{
${ }^{8}$ We note also that $T_{e q}$ gives a size which maximizes the present values at date of their entry of the incomes of all entrants. For entrants at date $\tau$, the present value of income net of housing costs is

$$
\int_{\tau}^{T} L S(\nu t) e^{-\delta(t-\tau)} d t+\frac{e^{-\delta(T-\tau)}}{1-e^{-\delta T}} \int_{0}^{T} L S(\nu z) e^{-\delta z} d z-H
$$

The first term is the present value to entrants at time $\tau$ of their income during the remaining growth time of the city. In the second term, the integral expression gives the present value of income net of housing costs for any resident of the city in steady state during the growth cycle of each successive new city. This cycle repeats indefinitely but only starts after a time length $(T-\tau)$ (hence the term

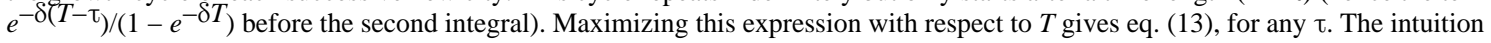
is that changing $T$ only changes final income and the future income net of rent cycles after the city stops growing; these changes apply to everyone regardless of date of entry.
} 
From Proposition 2, the integral terms on the right-hand side are positive iff $T_{e q}>T_{\text {opt }}$. Thus $T_{e q}>T_{\text {opt }}$ iff the term on the left-hand side is positive.

The interpretation of proposition 3 is direct. Cities are too large [small] if the present value of externalities created by a marginal migrant in a new city is greater [less] than the present value of externalities created by that migrant in a stationary city, over the new city's growth interval. The condition depends on how externalities vary with city size. For example, if the externality is increasing in city size, as with the commonly used case in which $x(n)$ is isoelastic, the present value of externalities in an old city is greater than in new city. New cities start up too soon and stationary sizes are too small, because the ignored benefits of diverting migrants to a new city are less than the ignored benefits of adding people to an old city. However, the effect can go the other way, as would be the case if the positive externality declined with city size (for example, due to congestion externalities).

The fact that this equilibrium without city governments can result in smaller city sizes than the social optimum contrasts with traditional perfect mobility analyses where a new city only forms when the real income of a worker in a growing city falls to the level of $L S(0)$ (i.e. $L S(0)=L S(v T)$ ), where it pays people to leave the city, regardless of whether others follow.

The co-ordination failure problem of static models is solved here because builders commit to new city development through initial fixed $H$ investments and have perfect foresight. Now the comparison of equilibrium with optimum size just turns on the present value of marginal externalities in new versus old cities, as one would expect from applied welfare economics in a dynamic context.

\subsection{Implementing an Optimal Solution: Pigouvian Taxation}

Implementation of the optimum is, in principle, straightforward. A national government announces a subsidy schedule in which subsidies are a function of city size. Builders thinking of starting construction in a new city know that migrants to the city are guaranteed this schedule as the city grows, and then when it is stationary. The subsidies are financed out of lump sum national taxes which could be on the entire population, on all urban residents, or on land rents.

Proposition 4-If the national government enacts a Pigouvian subsidy schedule for residents of all cities, $s(t)=E X(v t)$, then the competitive equilibrium without city governments will be socially optimal.

Proof: In equation (12), replacing $L S(v t)+s(t)$ by $L S(v t)+E X(v t)=M S(v t)$, the new version of (13) is condition $\left(7^{\prime}\right)$.

The proposition is intuitive, since the only distortion present in the competitive equilibrium is workers' failure to internalize the externalities they create for other workers. ${ }^{9}$ This solution, like the competitive one without city governments, has fluctuating housing rents according to equation (16). ${ }^{10}$ Note that, in the solution, there is an issue of whether national governments can credibly commit to long term national subsidy schedules. 


\subsection{Competitive equilibrium with private local governments}

We turn now to a regime in which there are large private agents or property developers. A well known result from the literature on urban systems with perfectly mobile resources is that the presence of such large agents can secure an efficient city size (Henderson 1974, Rossi-Hansberg and Wright, 2007). We formulate the problem here for the case of private local governments determining optimal subsidy paths; in Henderson and Venables (2005) we show the solution extends to public governments, where voters at each instant determine subsidies. Since the analysis confirms the usual result that local governments can internalize externalities and implement efficient solutions, our presentation is brief and focuses on the important, distinctive features that arise in a dynamic context with sequential city formation, compared to the usual analysis. Here, local governance affects the income distribution between early and later entrants to a city, dramatically changes housing market outcomes, involves debt accumulation by local governments, and requires institutions that support such financing.

Following Henderson (1974) we assume that, at any instant, there is an unexhausted supply of potential large developers who each own all the land that will ultimately be used in their individual city and who collect all land rents in their city. They can borrow in capital markets and can subsidize worker-firms. However, they face competition from existing and other potential new cities and are induced to offer migrants subsidies to enter their city. These subsidies are guaranteed for all time. An example for the USA are contracts offered to new firms in a city that give tax breaks or offer wage subsidies over sustained periods of time. We continue to assume that housing is constructed by perfectly competitive builders and rented on a spot rental market, but we also look at the case where the land developer, or private government owns all housing. Housing rents remain distinct from land rents: land rents paid to the developer at each instant equal the rent from the urban land rent gradient.

To find the equilibrium we proceed as follows. Price-taking builders, mobile workers, competitive determination of land rent gradients within each city, and imposition of a stationary equliibrium are as before. As cities form sequentially, the developer of each new

\footnotetext{
${ }^{9}$ It is not essential the subsidy path employed by the national government follow the Pigouvian one. By comparing $\left(7^{\prime}\right)$ and $(13)$ it is only necessary that $s(t)$ be constructed to satisfy

$$
\int_{0}^{T}[s(t)-s(T)] e^{-\delta t} d t=\int_{0}^{T}[E X(\nu t)-E X(\nu T)] e^{-\delta t} d t
$$

so that the present value of subsidies in a new city compared to an old city are equal to the difference between the present value of externalities in a growing and a stationary city. As an example of an alternative subsidy path, the national government could set $s(T)=$ 0 . Then the present value of subsidies offered over the growth of a new city should equal the difference between the present value of the externality in that city, and the present value of the externality in the old city, which can be positive or negative according to whether competitive equilibrium cities, absent policy, are too large or too small as in Proposition 3. $1_{\text {Now }}$

$$
\hat{h}(t)=L S\left(\nu T_{o p t}\right)+s\left(T_{o p t}\right)+\delta H-[L S(\nu t)+s(t)]=M S\left(\nu T_{o p t}\right)-M S(\nu t)+\delta H .
$$
}

The swings in housing prices and hence also real income will be greater than without national government intervention, since $M S$ has larger swings than $L S$. This raises the possibility that the condition for house rents to be non-negative could be violated, in the sense that Assumption A4 does not ensure that $\delta H>M S\left(v T_{o p t}\right)-M S(v t)$ for all $t$. 
city chooses a subsidy schedule, $s_{i}(t)$, to maximize profits, subject to the constraints of free mobility of workers and construction decisions of builders. Developer profits are the land rents earned in her city net of subsidy payments,

$$
R_{i} \equiv \int_{0}^{\infty}\left[T R\left(n_{i}(t)-n_{i}(t) s_{i}(t)\right] e^{-\delta t} d t\right.
$$

and free entry of developers means that equilibrium profits will be zero. Free mobility requires that the per worker subsidy in any city at any instant is consistent with workers earning the current real income, $w(t)$, in the national labor market. Construction decisions require that builders in the current growing city would prefer to build in the growing city as opposed to any stationary city, the no-switch condition in (12).

Proposition 5-Equilibrium with competitive private city governments supports the social optimum. Workers' real income is constant through time in all cities at level $w=M S\left(v T_{o p t}\right)$ $-\delta H$. Rents are constant through time in all cities at a level $\delta H$. Subsidy payments $s(t)$ vary across the life of the city, satisfying $w=L S(v t)+s(t)-\delta H$.

Proof: The objective of the developer of city $i$ is to maximize the present value of rents net of subsidy payments, subject to the no-switch condition as in (12), which already incorporates the behaviour of mobile workers and far-sighted competitive builders. The instruments are the subsidy schedule $s_{i}(t)$ together with terminal date $T_{i}$ at which the city stops growing, after which the subsidy $s_{i}\left(T_{i}\right)$ is constant. Thus, we solve the program

$$
\begin{gathered}
\max _{s_{i}(t), T_{i}} \quad R_{i} \equiv \int_{0}^{T_{i}}\left[T R(\nu t)-\nu t s_{i}(t)\right] e^{-\delta t} d t+\left[T R\left(\nu T_{i}\right)-\nu T_{i} s_{i}\left(T_{i}\right)\right] \frac{e^{-\delta T_{i}}}{\delta} \\
\text { s.t. } \quad \int_{\tau}^{T_{i}}\left[L S(\nu t)+s_{i}(t)-(L S(\nu T)+s(T))\right] e^{-\delta(t-\tau)} d t \\
+\left[L S\left(\nu T_{i}\right)+s_{i}\left(T_{i}\right)-(L S(\nu T)+s(T))\right] \frac{e^{-\delta\left(T_{i}-\tau\right)}}{\delta} \geq 0, \quad \tau \in\left[0, T_{i}\right] .
\end{gathered}
$$

where $L S(v T)$ and $s(T)$ are respectively the earnings of workers in a stationary city and the equilibrium subsidy in stationary cities. In Appendix 4, we prove that the constraint holds with equality for all $\tau \in\left[0, T_{i}\right]$, so $s_{i}(t)=L S(v T)+s(T)-L S(v t)$, which says simply that the subsidy is set at the lowest rate that attracts builders and workers (satisfying the no-switch condition) given existing cities are offering $L S(v T)+s(T)=w \overline{+} \delta H$. This enables us to substitute the constraint directly into the objective and, noting that $T S(v t)=T R(v T)-$ $v t L S(v t)$ (Table 1) the optimisation programme can be written as

$\max _{T_{i}} \quad R_{i} \equiv \int_{0}^{T_{i}}[T S(\nu t)-\nu t(L S(\nu T)+s(T))] e^{-\delta t} d t+\left[T S\left(\nu T_{i}\right)-\nu T_{i}(L S(\nu T)+s(T))\right] \frac{e^{-\delta T_{i}}}{\delta}$

Optimal choice of $T_{i}$ gives first order condition

$$
M S\left(\nu T_{i}\right)=L S(\nu T)+s(T)
$$


With free entry of developers, in equilibrium their profits, $R_{i}$, must be zero. Using (21) in $\left(20^{\prime}\right)$ and integrating by parts (applying (A4) and then (A5)) and setting profits equal to 0 , we get

$$
R \delta / \nu=\int_{0}^{T}[M S(\nu t)-M S(\nu T)] e^{-\delta t} d t=0
$$

The value of $T$ solving equation (22) characterizes city size in the large developer case and, from equation ( $7^{\prime}$ ) of proposition 1 , its value is $T_{\text {opt }}$. There remain two issues. First, the optimization problem has workers flowing smoothly into a new city at rate $v$, giving population $v t$. Appendix 4 shows that a developer could not profitably induce a jump in population to some discrete initial size. Second there is the issue of why the subsidy path needs to be guaranteed. Consider dates $t>T_{\text {opt }}$. At such dates all housing construction in the city is sunk, so any reduction in $s(t)$ would be exactly matched by a reduction in house rents. The developer can therefore expropriate whoever owns the housing stock. In order for housing construction to take place, the developer has to commit to not do this, so the full time path of subsidy payments to workers must be guaranteed.

In the developer equilibrium, residents have a flat real income schedule inclusive of subsidies over all time, in contrast to Section 4. This has two further implications. First, there are no rent cyles, of the type illustrated in figure 2. As income streams are flattened, so are rents. Second, in Section 4, workers who enter the city system during a city's growth period have higher present values of incomes than those who enter at the very beginning/end of the period. In the present case, optimization by the developer extracts this surplus, so that incomes of all entrants are the same regardless of date of entry.

In Henderson and Venables (2005) we prove a related corollary that provides another perspective on the results. Competition induces the developer to pay the highest constant income possible, given zero profits. That is, competition to form the current new city requires the developer to pay the highest income possible to the initial residents (so they do not go to other potential new cities), subject to the no-switch constraint that building does not later resume in old cities. That constraint requires that later residents are paid no less than initial ones; i.e. everyone is paid a constant income. If later residents were paid less, then rents would rise in old cities and induce builders to construct houses there because the no switch condition is violated.

\subsection{Financing city development}

Critical to being able to offer the constant real income $w=M S\left(v T_{o p t}\right)-\delta H$ at each instant is the ability of the developer to borrow and accumulate debt, so as to smooth income streams. The path of debt incurred by the developer is implicit in the equilibrium outlined above, but here we draw it out explicitly. City debt at date $z \in[0, T]$ is given by the value of cumulated subsidy payments less land rents collected, or

$$
D(z)=\int_{0}^{z}(\nu t s(t)-T R(\nu t)) e^{\delta(z-t)} d t
$$




$$
=e^{\delta z} \int_{0}^{z}(\nu t[M S(\nu T)-A S(\nu t)]) e^{-\delta t} d t
$$

where integration and the discount factor cumulate past expenditures and the interest on them. Equation $\left(23^{\prime}\right)$ comes from noting that $s(t)=L S(v T)+s(T)-L S(v t) \equiv L S(v T)+s(T)-$ $A S(v t)+A R(v t) \equiv M S(v T)-A S(v t)+A R(v t)$. The debt path is described by the following corollary.

Corollary 1-Total city debt rises monotonically with city growth up to the last instant of development. Per person debt is declining towards the end of a city's growth path. Postgrowth, land rents collected exactly equal subsidies paid plus interest payments on the debt.

\section{Proof: See Appendix 4.}

The underlying paths describing city finance are illustrated in Figure 3 which shows an example of a subsidy schedule, per worker interest charges on the debt, and the level of subsidy minus land rent. Note that subsidies per worker decline and then rise again, mimicking the inverse of the $L S$ path so as to maintain constant income. Debt accumulates according to the gap between rents collected versus subsidies paid plus accumulated interest on the debt.

It is essential to this argument that the city developers can neither renounce its debt, nor expropriate house-owners. Clearly, there is an incentive for a stationary city - one which has finished borrowing and in which house construction is complete - to renounce debt. The only collateral for this debt are the city assets, in our model just the housing stock. However builders will not provide housing if it is likely to be seized by debt holders, and lenders will not lend unless there is assurance of repayment. Furthermore, once house construction is complete there is also an incentive for developers to expropriate house-owners by cutting subsidy payments. The final incidence of this falls on housing rent, and builders will not provide housing if they are vulnerable to such expropriation. Note however that we can construct an identical equilibrium in which the developer owns the housing and subsidy payments need not be guaranteed. Once the developer owns housing, in order to retain residents and cover all costs including the debt payments (which now increase by housing costs), the developer would choose to offer the $s(t)$ schedule, net of housing costs, that we constructed above. Renunciation of obligations is a fundamental problems in city finance.

Finally we note the developer equilibrium has a dynamic version of the Henry George theorem. In the static version, subsidies equal externalities and total subsidies exactly are paid out of land rents. In the dynamic version, the present value of rents still covers the present value of subsidies paid out. However there is no requirement at any instant that externalities equal subsidies nor that the present value of total subsidies, $\int_{0}^{T} \nu t s(t) e^{-\delta t} d t$, equals the present value of total externalities, $\int_{0}^{T} \nu t E X(\nu t) e^{-\delta t} d t$. Rather the requirement is that the present value of externalities, $\int_{0}^{T} E X(\nu t) e^{-\delta t} d t$, created by the marginal entrant from a city's initial occupation onward equals the present value of subsidies, $\int_{0}^{T} s(t) e^{-\delta t} d t$, 
paid to that entrant ${ }^{11}$. What matters is the present value of the externalities of the marginal entrant.

\section{Extensions and Evidence}

We have assumed so far that all cities have identical and stationary underlying technologies. As a consequence they all have identical terminal size and growth is strictly sequential. In this section, using an example, we illustrate how these assumptions can be relaxed, allowing technology to vary across cities and over time and having a fixed interval of national urban population growth. This introduces cross-sectional differences in existing city sizes and periods of repeat growth in each city. The motivation is to show the model generalizes retaining basic properties. In Henderson and Venables (2008), we develop analytically a generalization, where technology just varies across cities. There we assume urban sites differ in production amenities such as natural harbors or inland waterways which affect shipping costs and received prices, as well as in consumer amenities related to weather, water resources, and mountains. Suppose city sites are ranked so that $L S_{1}(n)>L S_{2}(n)>$ $L S_{3}(n)>\ldots \ldots . . L S_{z}(n)$, and builders always (rationally) choose the highest ranked unoccupied site to start a new city. With that framework, as suggested in Krugman (1996) and Gabaix and Ioannides (2004), we show that one can generate a size distribution of cities in the model that obeys Zipf's Law, based on the idea that geographic amenities, or the quality of possible city locations follow a power law distribution (e.g., Newman 2005)

In this section we also review some empirical evidence in the literature suggesting our growth scenario is consistent with the data.

\subsection{Extensions}

We now illustrate that the model generalizes to allow technology to differ across cities and time and to allow urban population growth to cease at some point. With technology also varying over time nationally, we replace the function $L S(n(t))$ by $L S_{i}\left(n_{i}(t), t\right)$. Time variations in technology might be due to changes in production or commuting technology which facilitate increases in city size, where the latter is emphasized in the literature on city development (Mills, 1972). We illustrate equilibria by applying the algorithm in (11) where builders always build in the highest profit cities. We assume that urban sites are heterogeneous, there is continuous technical progress at a constant rate during $t \in[0, T]$; this progress is specified to shift $L S$ functions up and out, so as to continuously increase optimal city sizes. And we assume that, while population growth continues at rate $v$, it only does so for a fixed length of time, $T$, and then ceases. Building in cities that yield the highest profit, given the duality between rent maximisation and income maximisation problems, is also equivalent to building in cities which offer the highest present value of incomes, $\operatorname{LS}(n(t))$, relative to other cities, where we denote the present value of incomes from construction date $\tau$ by

${ }^{11}$ This requirement follows from equation $\left(7^{\prime}\right)$, given

$$
\int_{0}^{T} E X(\nu t) e^{-\delta t} d t=\int_{0}^{T}[M S(\nu t)-L S(\nu t)] e^{-\delta t} d t \text { and } \int_{0}^{T} s(t) e^{-\delta t} d t=\int_{0}^{T}[M S(\nu T)-L S(\nu t)] e^{-\delta t} d t .
$$




$$
V_{i}(\tau) \equiv \int_{\tau}^{\infty} L S_{i}\left(n_{i}(t), t\right) e^{-\delta(t-\tau)} d t
$$

Figures $4 \mathrm{a}, \mathrm{b}$, and c illustrate outcomes for one example, where functional forms are given in Appendix 5 (and also used in drawing other figures). Figure 4a gives the population of each city as a function of time, where in equilibrium cities are occupied in order, starting with the city with the highest natural amenity level. We see that, with our functional forms, just five cities develop, since the system becomes stationary at $T$. Each city first experiences an initial period of solo growth with sequential city formation, and then alternates stationary periods when a new city is experiencing an episode of solo growth, with periods of continued growth. Technical progress as modelled here increases agglomeration benefits, so part of resumed episodes of growth is expanding to more take advantage of these benefits.

Figure $4 \mathrm{~b}$ gives the values $V_{i}(\tau)$ along the equilibrium. Each city is growing when it offers the maximum value of $V_{i}(\tau)$, and we see that, for example, in the interval when cities 1,2 , and 3 are all growing, they are offering new migrants the same present values of incomes and builders thus the same present value of rents. The equilibrium path of house rents where mobile workers are indifferent between all cities at all dates is illustrated in Figure $4 \mathrm{c}$ for city 1 and, as in Figure 2, we see rent cycles. Thus, at the date builders switch to city 2, where house rents are $\delta H$ from equation (15), current incomes in city 2 are small compared to city 1 . New migrants only choose city 2 because rents spike in city 1 , given that builders have ceased construction there.

The example shows how our approach can be generalised and how the main insights are robust. Other extensions are possible, but not pursued here. For example, we have analysed a situation where cities are subject to occasional, unanticipated shocks such as improvements in urban transport technology. Also we have generated continuous growth of all cities by introducing adjustment costs at each instant to city size expansion. There sequential growth involves the latest new city growing much more rapidly than existing cities for an interval.

\subsection{Evidence}

The data seem to support the idea of sequential city formation, with new cities growing from scratch without population losses for existing cities. In terms of population losses, for example, from 1900-1990 when the USA moved from being 40\% urban to $75 \%$ urban, Black and Henderson (2003) show that almost no metro areas and certainly no medium or larger ones experienced significant (over 5\%) population losses between decades. In a worldwide data set for 1960-2000 covering all metro areas over 100,000, Henderson and Wang (2007) identify 25 countries that start with just one metro area in 1960 and have more metro areas form during 1960-2000. Of these 25 initial metro areas, 22 experience no population losses in subsequent decades. Of the 3 that do, none lose population at the decade when new metro areas enter the picture; and each has a special circumstance (Phnom Penh in the 1970's and Latvia and Estonia where all cities lose population from 1990-2000). 
In an exhaustive study, Cuberes (2004) shows more generally that the data support the key features of sequential growth. Cuberes covers city populations in 52 countries drawn from various sources, using primarily metro area level data. The start date for each country depends on data availability, most lying in the range 1880 to 1930, with the earliest being 1790 (USA) and the latest 1953 (Uruguay). Cuberes first presents strong evidence that cities grow in sequence. He ranks the 5 largest cities at the start date for each country from 1 (largest) to 5 (smallest) and then plots which ranked city has the highest growth rate in each decade. Sequential growth should have city 1 growing fastest in the earliest decade(s), then city 2 in the next decade(s), then city 3 and so on. The data are noisy, but for most countries a regression line against time and rank of the fastest growing city (at each decade) has the hypothesized positive slope. In particular for today's developed countries, 12 out of 16 have a positive slope, and for today's medium and low income countries (where data start in the more modern era, post-1925), 14 of 17 countries have positive slopes (Cuberes, Table 5).

Correspondingly, Cuberes also shows that individual cities tend to have early periods of rapid growth (from their date of entry as a city), followed by slow growth and/or stagnation. Taking the starting top 5 cities in each country he shows there is an-inverted U-relationship between the share of the 5 cities in total national or total national urban population and time. Correspondingly, the inverted-U relationship between urban primacy (share of the largest city) and time is well established in the literature (e.g, Junius, 1999).

\section{Concluding comments}

In this paper we develop a dynamic model to analyze the problem of city formation and city size in an economy in which total urban population is increasing, an environment relevant for many developing countries experiencing rapid urbanization. The dynamic context has a number of advantages. It yields sequential formation of cities, where new cities grow from scratch to a stationary size as is more consistent with the worldwide data on city formation and growth, rather than instantly jump to that size. It enables the competitive equilibrium to be analyzed free of simple coordination failures. It allows us to see how prices of fixed housing assets vary between growing and stationary cities. And it enables us examine a role for city borrowing and debt accumulation.

We find that socially optimal city size is larger than in a static model; cities should grow beyond the point at which surplus per worker is maximized. The competitive equilibrium with no city governments may support cities that are larger or smaller than socially efficient, depending on how externalities vary with city size. In the competitive equilibrium housing prices in stationary cities cycle with the growth of a new city, mirroring the evolution of per worker income in the growing city, potentially an empirically testable finding. Then we show that large developers or public city governments can internalize the externalities and support the social optimum. These institutions also smooth the time path of housing prices in stationary cities and of income paths in new cities. But the institutional requirements for such equilibria are strong. We looked at extensions involving heterogeneity of cities and technical change to show our basic results are robust; and that, under appropriate conditions, the model generates a size distribution of cities following Zipf's Law. 


\section{References}

Abdel-Rahman, H.; Anas, A. Theories of Systems of Cities. In: Henderson, JV.; Thisse, J-F., editors. Handbook of Urban and Regional Economics, Volume 4, Cities and Geography. North Holland; 2004.

Anas A. On the Birth and Growth of Cities. Regional Science and Urban Economics. 1992; 22:243258.

Baron DP, Ferejohn JA. Bargaining in Legislatures. American Political Sceience Review. 1989; 83:1181-1206.

Black D, Henderson JV. A Theory of Urban Growth. Journal of Political Economy. 1999; 107:252284.

Black D, Henderson JV. Urban Evolution in the USA. Journal of Economic Geography. 2003; 3:343372.

Brueckner, J. Urban Growth Models with Durable Housing. In: Huriot, J-M.; Thisse, J-F., editors. Economics of Cities. Cambridge University Press; 2000.

Cuberes, D. The Rise and Decline of Cities. 2004. http://home.uchicago.edu/ dcuberes/David \%20Cuberes_files/page0002.htm

Duffie D, Geanakoplos J, Mas-Colell A, McLennan A. Stationary Markov Equilibria. Econometrica. 1994; 62:745-781.

Duranton, G.; Puga, D. Micro-Foundations of Urban Agglomeration Economies. In: Henderson, JV.; Thisse, J-F., editors. Handbook of Urban and Regional Economics, Volume 4, Cities and Geography. North Holland; 2004.

Fujita, M. Chapter 6 and Appendix F. Amsterdam: North Holland; 1978. Spatial Development Planning.

Gabaix, X.; Ioannides, Y. The Evolution of City Size Distributions. In: Henderson, JV.; Thisse, J-F., editors. Handbook of Urban and Regional Economics, Volume 4, Cities and Geography. North Holland; 2004.

Glaeser, EL. Discussion paper No 1932. Cambridge MA: Harvard Institute of Economic Research; 2001. The Economics of Location-Based Tax Incentives.

Glaeser EL, Gyourko J. Urban Decline and Durable Housing. Journal of Political Economy. 2005

Greenstone, M.; Moretti, E. Bidding for Industrial Plants: Does Winning a 'Million Dollar Plant' Increase Welfare?. 2004. http://papers.ssrn.com/sol3/papers.cfm?abstract_id=623122

Helsley R, Strange W. Matching and Agglomeration Economies in a System of Cities. Journal of Urban Economics. 1990; 20:189-212.

Helsley R, Strange W. City Formation with Commitment. Regional Science and Urban Economics. 1994; 24:373-390.

Henderson JV. The Sizes and Types of Cities. American Economic Review. 1974; 61:640-56.

Henderson, JV.; Wang, H-G. Regional Science and Urban Economics. 2007. Urbanization and City Growth.

Henderson, JV.; Venables, AJ. The Dynamics of City Formation: finance and governance. 2005. http:// www.econ.brown.edu/faculty/henderson/papers.html

Henderson, JV.; Venables, AJ. NBER WP\# 13769. 2008. The Dynamics of City Formation.

Ioannides Y, Overman H. Zipf's Law for Cities: an Empirical Examination. Regional Science and Urban Economics. 2003; 33:127-137.

Junius K. Primacy and Economic Development: Bell Shaped or Parallel Growth of Cities. Journal of Economic Development. 1999; 24(1):1-22.

Krugman P. Confronting the Mystery of the Urban Hierarchy. Journal of the Japanese and International Economics. 1996; 10:399-418.

Mills, ES. Studies in the Structure of the Urban Economy. Johns Hopkins University Press; 1972.

Newman MEJ. Power Laws, Pareto Distributions and Zipf's Law. Contemporary Physics. 2005; 46:323-353.

Rauch J. Does History Matter Only When Its Matters Little: The Case of City-Industry Location. Quarterly Journal of Economics. 1993; 108:843-867. 
Rossi-Hansberg E, Wright MLJ. Urban Structure and Growth. Review of Economic Studies. 2007 forthcoming.

Venables AJ. Spatial Disparities in Developing Countries: Cities, Regions, and International Trade. Journal of Economic Geography. 2005

World Bank. Entering the $21^{\text {st }}$ Century: World Development Report 1999/2000. Oxford University Press; 2000.

\section{Appendix 1: Commuting costs and rent gradients}

Population at distance $l$ from the CBD is $k l^{\theta}$ and commuting costs from this distance are $c l^{\eta}$, where $\theta=0$ or 1 , in respectively a linear or circular city and $\eta \geq 1$. $k$ represents the combination of lot size and geography of the city where, for example, in a circular city with lot size $1, k=2 \pi l$. Total population in a city of radius $l$ (or line length $l) \overline{\text { is: }}$

$$
n=\int_{0}^{\bar{z}} k l^{\theta} d l=\bar{l}^{1+\theta} k /(1+\theta), \text { so } \bar{l}=[n(1+\theta) / k]^{1 /(1+\theta)}
$$

Edge commuting costs are:

$$
c \bar{l}^{\eta}=c[n(1+\theta) / k]^{\eta /(1+\theta)} .
$$

Total commuting costs are

$$
T C=\int_{0}^{\bar{l}} k c l^{\eta} l^{\theta} d l=\frac{c k \bar{l}^{1+\theta+\eta}}{1+\theta+\eta}=\frac{c k}{1+\theta+\eta}\left[\frac{n(1+\theta)}{k}\right]^{\frac{1+\theta+\eta}{1+\theta}}
$$

We define $\gamma \equiv(1+\theta+\eta) /(1+\theta)>1$ and choose units (of lot size for a specific geography) such that $k=1+\theta$. Edge commuting costs and total commuting costs in Table 1 follow directly. Total land rent is population, $n$, times edge commuting cost times minus total commuting costs.

\section{Appendix 2: Proofs related to Proposition 1}

\section{A: Uniqueness}

This part shows $\int_{0}^{T}[M S(\nu t)-M S(\nu T)] e^{-\delta t} d t=0$ solves at a unique value of $T_{\text {opt }}$ where $\mathrm{n}_{\mathrm{opt}}=v \mathrm{~T}_{\mathrm{opt}}$ and $n_{\text {opt }}>n_{A}$. Assumption A3 on single peakedness tells us that the gradient $\partial\left(\int_{0}^{T}[M S(\nu t)-M S(\nu T)] e^{-\delta t} d t\right) / \partial T=-M S^{\prime}(\nu T)\left[1-e^{-\delta T}\right] \nu / \delta$ and is therefore decreasing until $v T_{A}=n_{A}$ and strictly increasing thereafter. The value of the integral is therefore strictly increasing through zero at $T=T_{o p t}$, ensuring existence of a unique solution where $n_{\text {opt }}>n_{A}$.

\section{B: Inefficiency of simultaneous development of multiple new cities}

In Proposition 1, where each city forms in sequence and grows to its optimal stationary size, the objective function can be rewritten in simplified form as 


$$
\Omega=\frac{1}{1-e^{-\delta T}}\left[\int_{0}^{T} T S(\nu t) e^{-\delta t} d t+\frac{T S(\nu T) e^{-\delta T}}{\delta}\right]-\int_{0}^{\infty} \nu H e^{-\delta t} d t
$$

The term in square brackets is the total surplus in a city founded at date zero and growing to date $T$ at where the surplus at every instant from then on is $T S(v T)$, with present value $\int_{T}^{\infty} T S(\nu T) e^{-\delta t} d t=T S(\nu T) e^{-\delta T} / \delta$. At $T$ another city is founded and the process repeats itself. The term multiplying the square brackets is the sum of the geometric series $1+\mathrm{e}^{-\delta T}+$ $\mathrm{e}^{-\delta 2 T} \ldots$, which represents sums the present value of all future cities. Optimization with respect to $T$ gives first order condition,

$$
\frac{\left[1-e^{-\delta T}\right]^{2}}{\delta e^{-\delta T}} \frac{d \Omega}{d T}=-\left[\int_{0}^{T} T S(\nu t) e^{-\delta t} d t+\frac{T S(\nu T) e^{-\delta T}}{\delta}\right]+M S(\nu T) \frac{\left[1-e^{-\delta T}\right] \nu}{\delta^{2}}=0 .
$$

This condition can be reworked to give $\left(7^{\prime}\right)$, where from integration by parts we know

$$
\left[\int_{0}^{T} T S(\nu t) e^{-\delta t} d t+\frac{T S(\nu T) e^{-\delta T}}{\delta}\right]=\left(\frac{\nu}{\delta}\right) \int_{0}^{T} M S(\nu t) e^{-\delta t} d t
$$

We also note for later use another integration by parts result:

$$
\left[\frac{1-e^{-\delta T}}{\delta^{2}}\right]=\int_{0}^{T} t e^{-\delta t} d t+\left[\frac{T e^{-\delta T}}{\delta}\right]
$$

In the alternative solution where $k$ cities form and grow simultaneously before reaching their stationary state, the new objective function, net of housing costs, is

$$
\Omega^{*}=\frac{1}{1-e^{-\delta T}}\left[\int_{0}^{T} T S(\nu t / k) e^{-\delta t} d t+\frac{T S(\nu T / k) e^{-\delta T}}{\delta}\right]
$$

Optimising gives the same form to the first order condition for $T$ as in $\left(7^{\prime}\right)$ (although different optimal values, as functions depend on $v t / k$ ). The first order condition for $k$ is

$$
\left[1-e^{-\delta T}\right] \frac{k}{\nu} \frac{d \Omega}{d k}=\delta^{-1}\left[\int_{0}^{T}\left(M S\left(\frac{\nu}{k} t\right)-M S\left(\frac{\nu}{k} T\right)\right) e^{-\delta t} d t\right]-\left[\int_{0}^{T}\left(M S\left(\frac{\nu}{k} t\right)-M S\left(\frac{\nu}{k} T\right)\right) t e^{\delta t} d t\right]
$$

On the RHS, given eq $\left(7^{\prime}\right)$, the first term in square brackets is zero (implied by the first order condition defining the optimal $T$ in this context ). Given assumption A3, $M S$ is strictly increasing to a peak before it is strictly decreasing. Then the second term in square brackets in (A6) must be positive: relative to the first term of (A6), the same items, 
$M S\left(\frac{\nu}{k} t\right)-M S\left(\frac{\nu}{k} T\right)$, in the expression when negative get low $t$ weights and when positive ones high $t$ weights). Thus the whole condition is negative, indicating that increases in $k$ reduce welfare. $k$ is bounded below by one, the solution we characterise.

\section{C: Inefficiency of jump solution}

If workers can be moved between cities at zero cost then a new city size can jump to some size. Suppose that instead of growing continuously through interval $[0, T]$ a new city jumps at date $\zeta$ to population $v \zeta$. For $t \in[0, \zeta]$ new migrants accumulate in old cities. Pure irreversibility is not sufficient to prevent such a jump; if the fixed cost of housing is small, then it can be efficient to have some jump in city size - to store people near $n_{\text {opt }}$ in old cities for an interval of length $\zeta$, to avoid the low AS values in a new city until it optimal to move a mass of people into a new city. The cost of this jump is that new migrants have to be accommodated in existing cities until they jump to a new city where housing is then built for them; and we need to make this cost sufficiently high. In particular, the present value of the extra housing costs incurred over $[0, T]$ is:

$$
C=\delta H \nu \zeta \int_{0}^{T} e^{-\delta t} d t+H \nu \zeta e^{-\delta \zeta}-H \nu \int_{0}^{\zeta} e^{-\delta t} d t
$$

The first term is the cost of holding $v \zeta$ houses in old cities. The remaining terms give the cost saving in the new city from the fact that $v \zeta$ units of housing are constructed at date $\zeta$ (second term) rather than being constructed continuously through $t \in[0, \zeta]$. Using integral (A5), this expression integrates to:

$$
C=\delta H\left[\nu \zeta \int_{\zeta}^{T} e^{-\delta t} d t+\int_{0}^{\zeta}(\nu \zeta-\nu t) e^{-\delta t} d t\right]
$$

which can be interpreted directly as the present value of the opportunity cost of having empty houses. The term outside the square brackets is the opportunity cost per house. Inside, the first term is the number of houses that are empty for $t \in[\zeta, T]$, and the second the number that are empty at date $t \in[0, \zeta]$, each discounted back to date zero.

The benefit of jumping is the value of putting new workers arriving during $t \in[0, \zeta]$ in an established city with average surplus $A S(v T)$ rather than in a growing city with surplus $A S(v t)$

$$
B=\int_{0}^{\zeta} \nu t A S(\nu T) e^{-\delta t} d t-\int_{0}^{\zeta} \nu t A S(\nu t) e^{-\delta t} d t
$$

Hence, the net benefit is

$$
\begin{aligned}
& C-B=\delta H\left[\nu \zeta \int_{\zeta}^{T} e^{-\delta t} d t+\int_{0}^{\zeta}(\nu \zeta-\nu t) e^{-\delta t} d t\right]-\int_{0}^{\zeta} \nu t[A S(\nu T)-A S(\nu t)] e^{-\delta t} d t \\
= & \delta H\left[\nu \zeta \int_{\zeta}^{T} e^{-\delta t} d t+\int_{0}^{\zeta}(\nu \zeta-2 \nu t) e^{-\delta t} d t\right]+\int_{0}^{\zeta} \nu t[\delta H-(A S(\nu T)-A S(\nu t))] e^{-\delta t} d t
\end{aligned}
$$


Setting (A10) equal to zero defines the value of $H$ above which it is not profitable to jump. In the second line, the first square bracketed expression is positive. [Note, in the second line, the second integral in that first square brackets is positive. In that integral, the term in parentheses under that integral is declining in $t$; the integral is zero without discounting; and thus it is positive with discounting.]. A sufficient condition for $C>B$, then is that the second square bracketed term is also positive. Given at the optimum that $A S(v T)>A S(0)$, assumption A4, which requires $\delta H \geq A S\left(n_{A}\right)-A S(0)$, ensures that this. Since $A S\left(n_{A}\right)$ is the maximum value of $\mathrm{AS}$ and $A S(0)$ the minimum, then at the optimum $A S(v T)-A S(v t) \leq$ $A S\left(n_{A}\right)-A S(0)$ for all $t \in[0, T]$.

\section{Appendix 3: Proofs related to proposition 2}

a. A unique $T$ solves (13). Equation (13) takes value zero at $T=0$. Its gradient is given by $\partial\left(\int_{0}^{T}[L S(\nu t)-L S(\nu T)] e^{-\delta t} d t\right) / \partial T=-L S^{\prime}(\nu T)\left[1-e^{-\delta T}\right] \nu / \delta$ and is therefore decreasing until $T_{L}$ and strictly increasing thereafter (by strict concavity of the function $L S$, assumption A1). The value of the integral is therefore strictly increasing through zero at $T=T_{e q}$, ensuring existence of a unique solution. Note for equation (13) to hold $L S\left(v T_{e q}\right)>L S(0)$.

b. The no-switch condition (17) is satisfied with inequality for all $z \in(\tau, T)$. This follows since $L S$ is initially strictly increasing and then decreasing, noting that terms beyond $\tau+T_{i}$ are zero. As $z$ rises from $\tau$, initially negative terms in $\int_{z}^{\tau+T_{i}}\left[L S\left(\nu(t-\tau)-L S\left(\nu T_{j}\right)\right] e^{-\delta(t-z)} d t\right.$ in (17) are dropped making the expression positive, with it only going to 0 again at $T$.

c. $h(t)>0$ for all $t$. This condition will be satisfied if $\delta H>L S\left(v T_{L}\right)-L S\left(v T_{e q}\right)$. Given the right-hand side is less than $A S\left(v T_{A}\right)-A S(0)$ in assumption $\mathbf{A 4}$, (the peak value of $L S$ is less than that for $A S)$, the condition is met under $\mathbf{A 4 .}$

\section{Appendix 4: Derivations, Section 5}

\section{1) Optimization problem (20)}

The Lagrangean corresponding to (20) is:

$$
\begin{gathered}
L \equiv \int_{0}^{T}[T R(\nu t)-\nu t s(t)] e^{-\delta t} d t+[T R(\nu T)-\nu T s(T)] \frac{e^{-\delta T}}{\delta} \\
+\int_{0}^{T} \lambda(\tau)\left[\int_{\tau}^{T}[L S(\nu t)+s(t)-(L S(\nu T)+S(T))] e^{-\delta(t-\tau)} d t+[L S(\nu T)+s(T)-(L S(\nu T)+S(T))] \frac{e^{-\delta(T-\tau)}}{\delta}\right] d \tau
\end{gathered}
$$

where the function is written with the constraint as an integral over $\tau$ from 0 to $T$ with multipliers $\lambda(\tau)$. The first order condition for $s(t)$ at date $z$ is

$$
\nu z e^{-\delta z}=\int_{0}^{z} \lambda(\tau) e^{-\delta(z-\tau)} d \tau
$$

from which $v e^{-\delta z}=\lambda(z)$. This is strictly positive at all dates, so the constraint binds at all times. Differentiating the constraint with respect to $\tau$ gives $s(t)+L S(v t)=L S(v T)+S(T)$. Maximizing (A11) with respect to $T$ has the solution $s(T)=E X(v T)$, given $E X(v T)=T R^{\prime}(v T)$ 
$+v T L S^{\prime}(v T)$ from Table 1 , where also these relationships imply $L S(v T)+S(T)=M S(v T) \equiv$ $L S(v T)+E X(v T)$.

\section{2) Jumps in city sizes are unprofitable}

The best possible jump for a developer is to instantaneously create a city of size $n_{A}$ and maximal real income, $A S\left(n_{A}\right)$. However, this is not profitable. Creating this new city would reduce house rents in existing cities according to equation (16), inducing residents to stay in old cities. To induce inter-city migration the developer would have to offer migrants enough income to drive rents in old cities to zero. But doing so is not profitable; assumption A4 is sufficient to ensure that $M S\left(v T_{\text {opt }}\right)>A S\left(n_{A}\right)-\delta H$, where $A S\left(n_{A}\right)-\delta H$ is the maximum income net of housing rent demanded by builders which a new city jumping to $n_{A}$ can pay migrants.

\section{3) Proof of Corollary 1}

For the debt expressions, from equation (23),

$$
\left.D(\tau)=e^{\delta t} \int_{0}^{\tau}(\nu t M S(\nu T)-T S(\nu t)]\right) e^{-\delta t} d t
$$

Using (A4) and (A5) this can be integrated to give

$$
\delta D(\tau)=\nu M S(\nu T)\left[\left(e^{\delta \tau}-1\right) / \delta-\tau\right]+T S(\nu \tau)-\nu e^{\delta \tau} \int_{0}^{\tau} M S(\nu t) e^{-\delta t} d t
$$

At date $\tau=T_{\text {opt }}$ this expression reduces to

$$
\delta D\left(T_{o p t}\right)=T S\left(\nu T_{o p t}\right)-M S\left(\nu T_{o p t}\right) \nu T_{o p t}
$$

(derived using equation $\left(7^{\prime}\right)$ ). This says that debt service is equal to total surplus minus the real income payment to workers, equal in turn to rents minus subsidies, so $\delta D(T)+v T s(T)=$ $T R(v T)$. Differentiating (A14) with respect to time, $\tau$,

$$
D^{\prime}(\tau) \frac{e^{-\delta \tau}}{\nu}=M S(\nu T)\left[\frac{1-e^{-\delta \tau}}{\delta}\right]-\int_{0}^{\tau} M S(\nu t) e^{-\delta t} d t=\int_{0}^{\tau}[M S(\nu T)-M S(\nu t)] e^{-\delta t} d t
$$

Thus $D^{\prime}(\tau) \rightarrow 0$ as $\tau \rightarrow T_{\text {opt }}$, from eq.( $\left.7^{\prime}\right)$. In the last term in (A16), the term in the integral is positive for small $\tau$, and then eventually declines monotonically, given assumption A3 (see Figure 1). Thus the integral starts positive, increases, and then decreases monotonically until it is zero at $T_{o p t}$, implying that total debt is always increasing up to $T_{o p t}$. Since $D^{\prime}(\tau) \rightarrow$ 0 as $\tau \rightarrow T_{o p t}$, it must be the case that, with strictly positive population growth until $T_{o p t}$, debt per worker peaks at some point and then declines. 


\section{Appendix 5: The Example in Figure 4}

The figure was constructed with both heterogeneity and technical change using:

$$
L S_{i}\left(n_{i}, t\right)=5 a_{i}+\left(n_{i} e^{0.0002 t}-0.4\left(n_{i} / a_{i}\right)^{2}\right) / 2-c n_{i}^{\gamma-1}
$$

with $c=0.2, \gamma=2$, and efficiency level $a_{i}$ following sequence $\{1.0,0.975,0.95,0.925,0.9$, $0.875,0.85\} \delta=0.008$ and $v=0.012$ for $t \in[0,1000]$ and $v=0$ thereafter. 

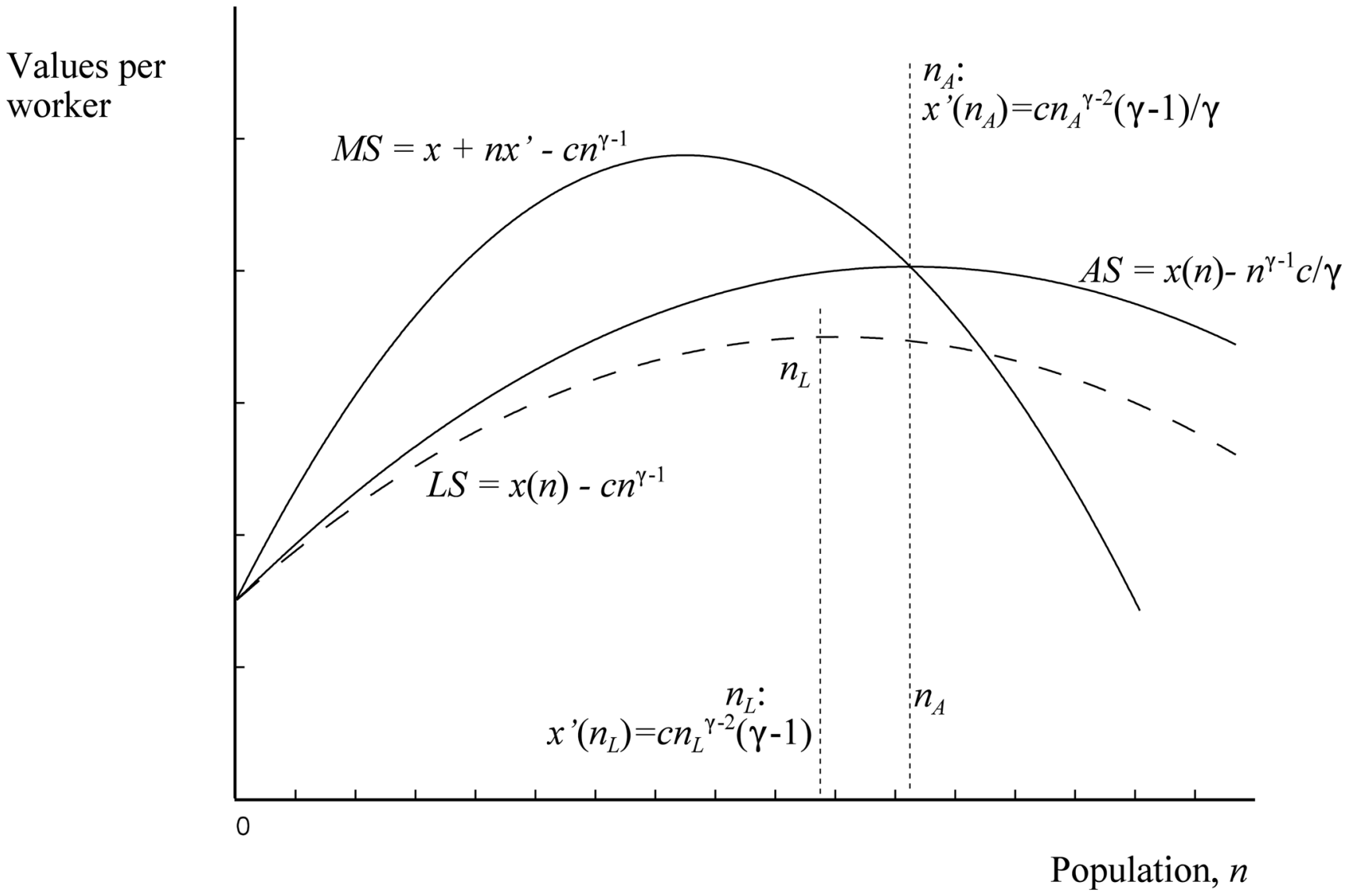

Figure 1.

Surplus per worker 


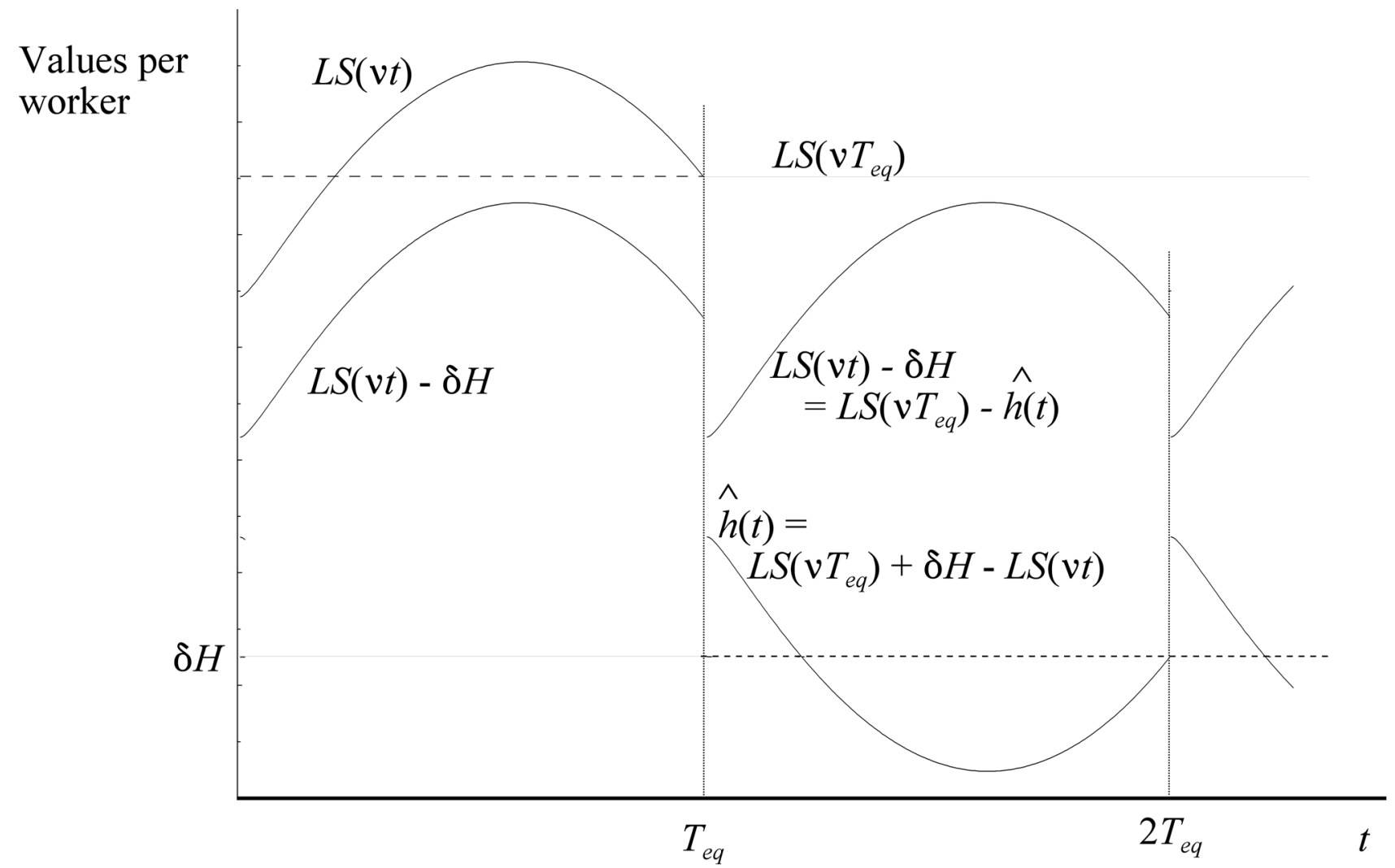

Figure 2.

Income and housing rent in the competitive equilibrium: 


\section{Values per worker}

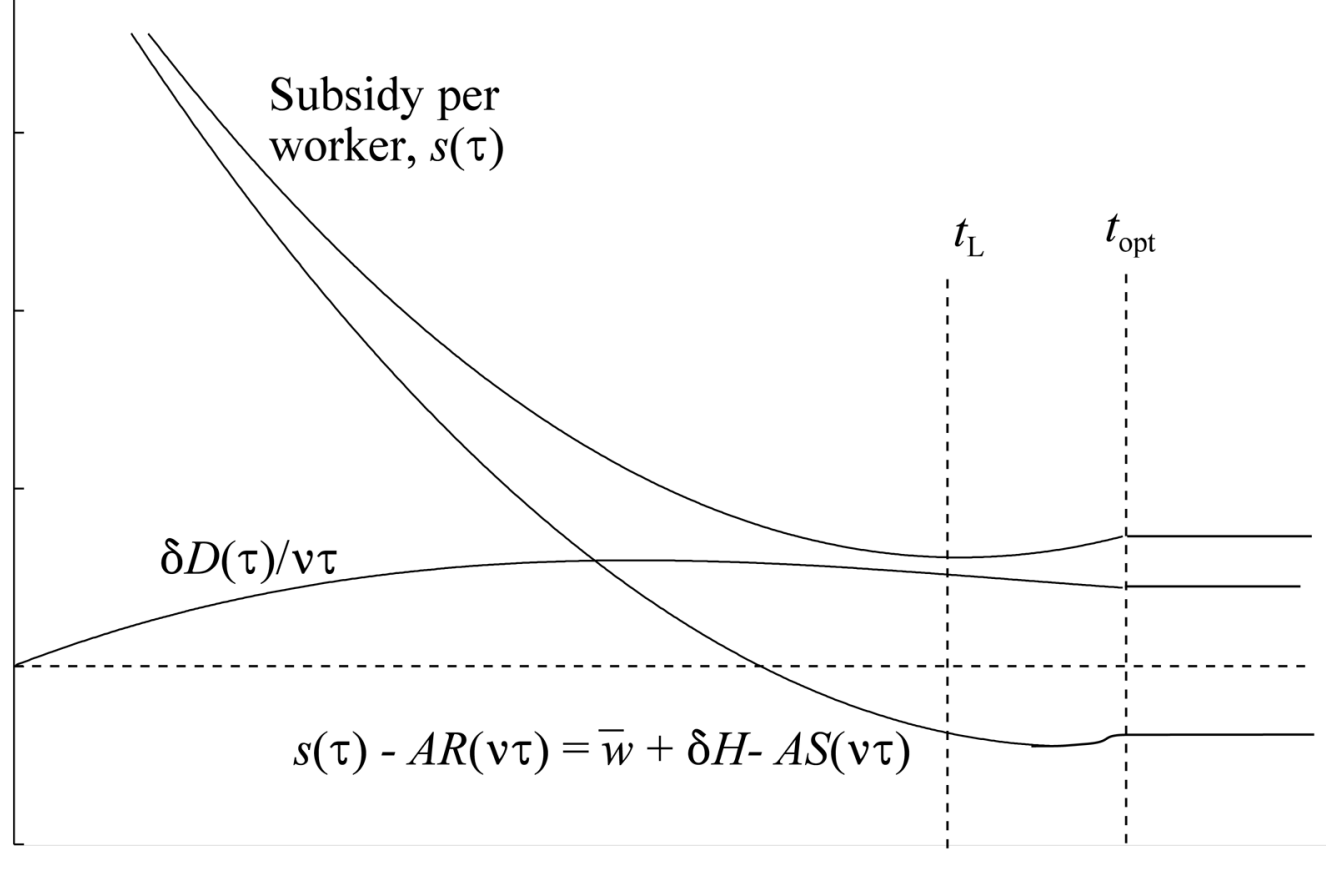

$\tau$

Figure 3.

Large developer's subsidy and debt service (per worker) 


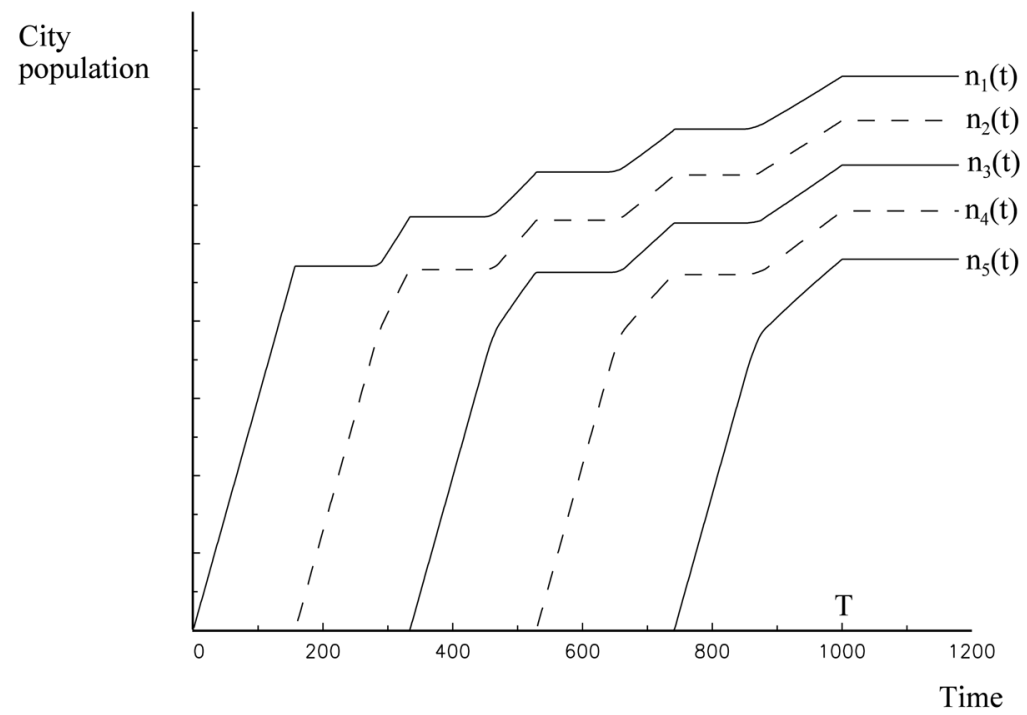

Figure 4a:

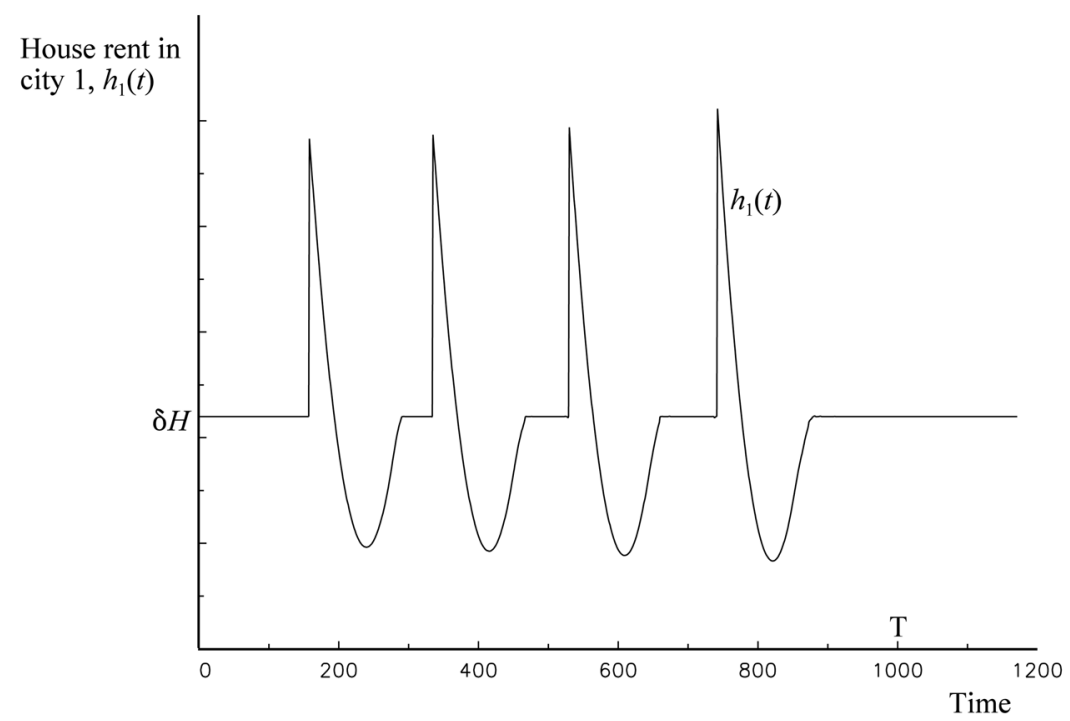

Figure 4c: 


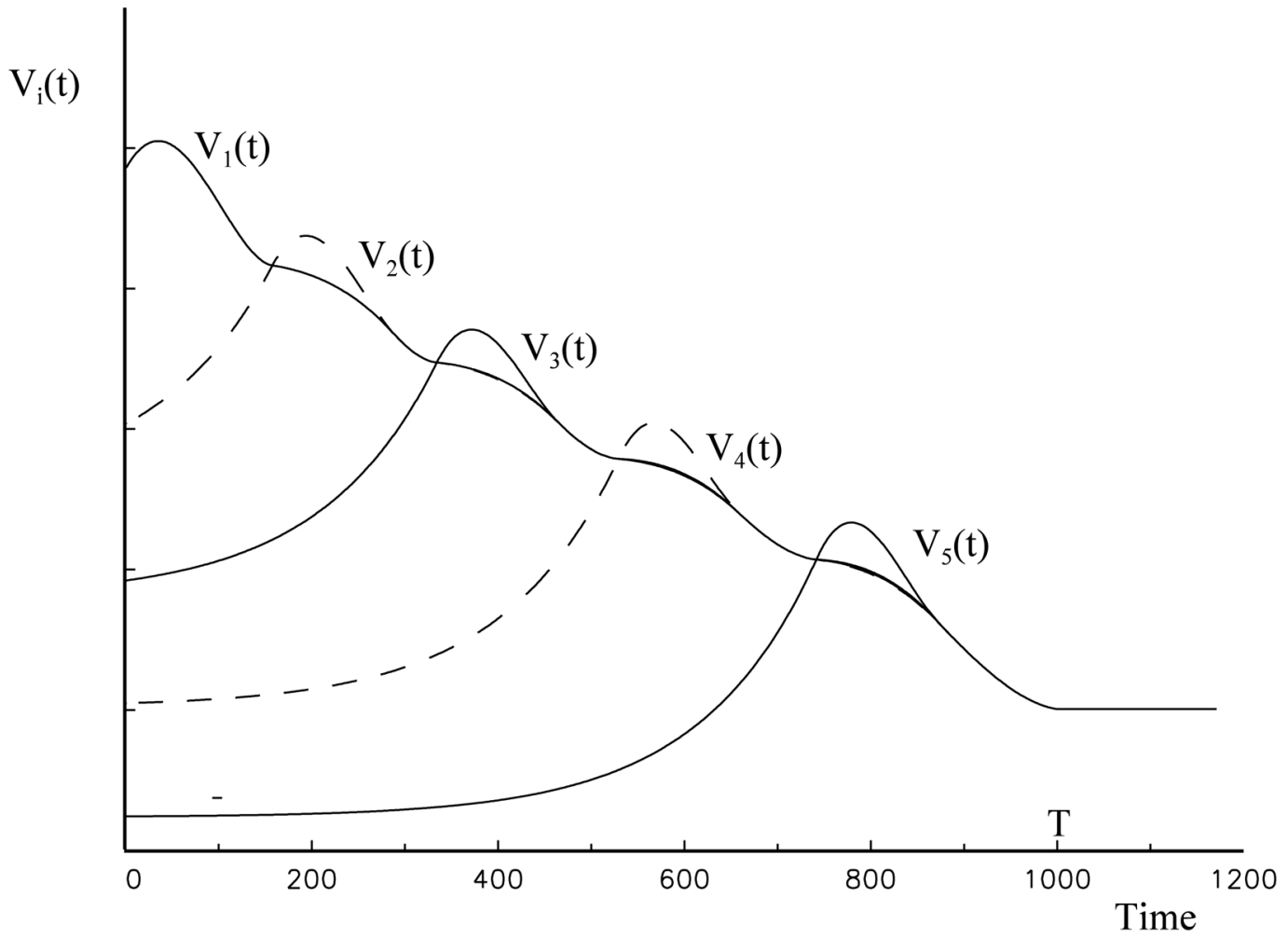

Figure 4b:

Figure 4.

Figure 4a: City size

Figure 4c: City 1 house rents

Figure 4b: Present values 


\section{Table 1}

Commuting costs, land rents, and surplus.

\begin{tabular}{|l|l|l|l|}
\hline edge commuting cost = land rent+commuting cost & $c n^{\gamma-1}$ & Total surplus: $T S(n)$ & $n x(n)-n^{\gamma}(c / \gamma)$ \\
\hline Total commuting costs: $T C(n)$ & $n^{\gamma}(c / \gamma)$ & Average surplus: AS(n) & $x(n)-n^{\gamma-1}(c / \gamma)$ \\
\hline Total land rent: $T R(n)$ & $n^{\gamma} c(\gamma-1) / \gamma$ & Marginal surplus: $M S(n)$ & $x(n)+n x^{\prime}(n)-n^{\gamma-1} c$ \\
\hline Average land rent: $A R(n)$ & $n^{\gamma-1} c(\gamma-1) / \gamma$ & Labour surplus: $L S(n) \equiv A S(n)-A R(n)$ & $x(n)-n^{\gamma-1} c$ \\
\hline & & Externality: $\operatorname{EX}(n)=M S(n)-L S(n)$ & $n x^{\prime}(n)$ \\
\hline
\end{tabular}

